\title{
ESTUDIO COMPARATIVO DE DOS METODOLOGÍAS APLICADAS PARA LA COMPRENSIÓN DE LA MÚSICA CONTEMPORÁNEA EN LA EDUCACIÓN SECUNDARIA OBLIGATORIA.
}

\author{
Ana María Botella Nicolás \\ Universitat de València \\ ana.maria.botella@uv.es
}

\section{Noèlia Lerma Granell}

IES San Vicente Ferrer de Valencia

n.lermagranell@gmail.com

\begin{abstract}
En este trabajo se pretende averiguar qué metodología resulta más idónea para la comprensión de la música contemporánea en la Educación Secundaria Obligatoria. Para ello, a través de un cuasi-experimento se han comparado los resultados obtenidos con la aplicación de dos metodologías diferenciadas, una tradicional basada en la clase magistral y otra basada en diferentes tipos de audición. Los resultados obtenidos después de la aplicación didáctica a nivel cuantitativo no fueron significativos, no obstante a nivel cualitativo, se pudo observar que los alumnos sometidos a la metodología experiencial tuvieron resultados más favorecedores ante la comprensión y audición de música clásica contemporánea.
\end{abstract}

Palabras clave: música clásica contemporánea, Educación Secundaria Obligatoria, metodología mixta, quasiexperimento, clase magistral, audición

In this paper we try to discover which methodology is more appropriate for the comprehension of the contemporary music in the Secondary Education. For that purpose by a quasi-experiment, mixed, qualitative and quantitative, the preserved results through the application of two different methodologies have been compared: a traditional one base on the masterly class and another based in different kinds of audition. The obtained results after the didactical application on the quantitative level weren't significant, however, on the qualitative level we could also observe that the pupils who subjected to that methodology had more advantageous results regarding to the comprehension of the contemporary classical music.

Keywords: contemporary classic music, Secundary Education, mixed methodology, quasi-experiment, masterly class, hearing

\section{INTRODUCCIÓN}

Esta investigación parte de una cuestión, la cual a su vez proviene de la práctica docente cotidiana en el contexto educativo de la Educación Secundaria Obligatoria: ¿Qué metodología resultará más idónea para la comprensión de la música contemporánea ${ }^{1}$ por parte del alumnado de la ESO?. Ante esto, la pretensión del trabajo que se presenta consiste en realizar una comparación de los resultados obtenidos, a través de una propuesta cuasi-experimental y mixta: cualitativa y cuantitativa, basada en la aplicación de dos metodologías diferenciadas, para la comprensión de la música contemporánea en el alumnado de $3^{\circ}$ de la ESO.

Por una parte, se ha aplicado una metodología tradicional basada en la clase magistral, la cual se destinó a un grupo control y por otra, una metodología más vivencial y práctica basada en diferentes tipos de audición, que fue aplicada a un grupo experimental. La finalidad de ambas metodologías es la comprensión de algunos aspectos estéticos comunes o habituales de gran parte de la música contemporánea. Los resultados obtenidos después de la aplicación del pre-test y post-test fueron comparados.

La música y consecuentemente la música contemporánea está presente en el currículo de la Enseñanza Secundaria Obligatoria de todo el estado español y debe formar parte de las programaciones de aula; así esta especificado en los Reales Decretos que desarrollan la legislación (vigente en el momento en el que se realizó esta investigación), la LOE (Ley Orgánica 2/2006, de 3 de Mayo, de Educación).

A pesar de la existencia de estudios que realizan propuestas para un acercamiento óptimo a la 
música contemporánea, utilizándola como recurso para el aprendizaje musical en general o profundizando en aspectos estéticos contextuales y sonoros propios de esta música, en la Educación Secundaria Obligatoria son escasos y poco utilizados. Urrutia (2012), en su estudio sobre la presencia y uso de la música contemporánea en la Educación Secundaria Obligatoria en el País Vasco así lo expone en relación con esta comunidad.

En los currículos de enseñanzas especiales de música, tanto en niveles profesionales como superiores, la presencia de la música contemporánea es también una evidencia, no obstante y como ocurre con frecuencia, lo expuesto a nivel curricular, no se corresponde con la práctica y la interpretación de obras de música contemporánea de características atonales se reduce a casos aislados en la mayor parte de los instrumentos en estudio. Así lo reflejan Ordoñana, Almoguera, Sesma y Laucirica (2006), cuando evalúan documentos curriculares de las enseñanzas profesionales de grado medio de música de las comunidades autónomas Vasca y Foral Navarra entre los años 2002 y 2003.

Pedagogos como Paynter (1999), Schaeffer (1988), Delalande (1995), Swanwick (1998), Cureses de la Vega (1998), Valls y Calmell (2010) resaltan las ventajas que aporta para el aprendizaje musical en general, utilizar la música contemporánea como recurso. Este tipo de música posee ciertos aspectos estéticos y sonoros como la notación no convencional, la atonalidad, la aleatoriedad o los sonidos no convencionales, que requieren para su enseñanza, la adopción de metodologías activas y motivadoras que propician que el alumno pueda ser creador, oyente e intérprete logrando por tanto un aprendizaje constructivo, significativo e inclusivo.

El problema viene cuando quien tiene que ofrecer este tipo de enseñanza no domina el lenguaje y la estética contemporánea en sus diversos niveles, y esta es la realidad que impera en muchos casos. Frecuentemente el profesorado de música de Educación Secundaria, por su formación académica y tradicional, la falta de materiales específicos o simplemente el no gusto por esta música reconoce no estar suficientemente formado para impartir este tipo de enseñanza musical y fomentar su comprensión, más allá de la clase magistral tradicional (Urrutia, 2012).

Este estudio tiene la pretensión de mejorar la propia práctica docente para un acercamiento idóneo, adecuado y motivador a la música contemporánea.

\section{ESTADO DE LA CUESTIÓN}

Actualmente se pueden encontrar trabajos e investigaciones sobre pedagogía y didáctica de la música contemporánea aplicados a diferentes contextos de estudios musicales, la mayoría de ellos provenientes del ámbito científico y musicológico. A pesar de esto, sigue siendo escasa la presencia de estudios sobre música contemporánea y su didáctica en el ámbito de la educación secundaria, especialmente en España. La mayor parte de los estudios que existen sobre didáctica y metodologías aplicadas a la música contemporánea pertenecen, como es obvio a la $2^{\mathrm{a}}$ mitad del siglo XX. Concretamente, a partir de la mitad de la década de los sesenta hasta la actualidad se encuentran numerosas propuestas, pero desde un punto de vista didáctico y como se ha expuesto anteriormente, son escasas las relacionadas con la Educación Secundaria Obligatoria.

Schafer, Paytner, Schaeffer o Delalande entre otros, representan al movimiento metodológico y didáctico pionero en Europa, con investigaciones y estudios que son todavía hoy referenciales en cuanto a la pedagogía musical innovadora e incluso en algún caso especializada en la música contemporánea: Sonido y Estructura, Paynter (1999), La música es un juego de niños, Delalande (1995), El nuevo paisaje sonoro, Schafer (1969), Tratado de los Objetos Musicales, Schaeffer (1988) representan estas nuevas líneas metodológicas. Aunque estas obras se conocen en nuestro país, existe una deuda pendiente en la pedagogía musical española, tanto en los aspectos fundamentales desarrollados en su entorno estético, como en su aplicación práctica y efectiva Cureses de la Vega (1998).

Además de estas obras pedagógicas y didácticamente referenciales, existen investigaciones que tratan aspectos de la música contemporánea relacionados con su comprensión estética, con la actitud hacia ella, su presencia en los diferentes currículos o incluso en aspectos relacionados con la 
psicología y la percepción. Urrutia (2012) cita a Bimberg (1987), quien a través de un estudio experimental concluyó que la actitud hacia la nueva música varía positivamente cuanto más conocimiento se tiene de ella, conocimiento adquirido a través de la audición comprensiva y el análisis. Hemsy de Gainza (1995) trata la didáctica de la música contemporánea en el aula de secundaria explicando y aportando su opinión respecto al tratamiento y secuenciación de los contenidos relacionados con este tipo de música, exponiendo además diferentes corrientes pedagógicas especializadas en esta música.

Más recientes son las investigaciones de Boal, Ilari y Monteiro (2006), quienes a través de un estudio empírico, con una muestra de niños de colegios de Brasil y Portugal, llegan a la conclusión de que la música contemporánea apenas es trabajada en el aula de ambas naciones, además de que el profesorado está escasamente formado en este tipo de música. Se compararon además las preferencias y actitudes musicales entre niños de diferentes edades, diez-once, trece-catorce en cada una de las naciones, llegándose a la conclusión general de una actitud de bastante rechazo y desconocimiento hacia la música contemporánea. No obstante, los resultados fueron un tanto más positivos en la muestra de niños de menor edad, que demostraron una mayor apertura y tolerancia hacia este tipo de música.

Mateos (2007) escribe una tesis sobre la música contemporánea y los futuros maestros de educación musical. Como conclusión expone la escasa presencia de la música contemporánea en la formación de éstos, así como una actitud poco receptiva motivada quizás por el desconocimiento de la materia que demostraron a través de los diferentes test y cuestionarios. Entre otras conclusiones, el autor no obstante afirma que a medida que se conoce el terreno de la nueva música o incluso con una mayor edad del oyente, más receptiva se vuelve la actitud hacia ella. Valls y Calmell (2010) realizan una propuesta didáctica para el acercamiento de la música catalana contemporánea a la escuela. Diseñaron una propuesta didáctica para primaria basada en la escucha, interpretación y creación de dicha música. Valls (2010) investiga sobre la presencia de la música contemporánea en el aula de primaria. En su estudio demuestra que los niños pequeños tenían una mayor predisposición y apertura hacia esta música, mientras que los de mayor edad mostraban rechazo hacia ella. Tras una intervención didáctica se demostró que el conocimiento y comprensión de esta música, favorece a un cambio de actitud y mayor predisposición hacia ella. Pascual (2011) realiza una interesante aportación a la didáctica de la música contemporánea en las aulas de Secundaria, así como un estudio del repertorio más utilizado en este contexto. Urrutia (2012) presenta una tesis acerca la presencia, valoración, conocimiento y actitud hacia la música contemporánea en la educación secundaria de la comunidad autónoma del País Vasco. Las conclusiones van en la línea de los estudios anteriores citados: se reafirma la escasa presencia de la música en la Educación Secundaria Obligatoria por diversos motivos que van desde la no preparación docente a la escasa relación del mundo docente con el compositivo, además de un desinterés general por parte del alumnado hacia la asignatura de música.

El estudio de la música y en particular de la contemporánea desde la perspectiva de la percepción y la psicología es también un campo bastante fructífero, no obstante en el contexto educativo que trata este artículo, las investigaciones o estudios son demasiado escasos. El acercamiento viene de la mano de autores pioneros como Francès (1958), Sloboda (1985), Haack (1992), o a través de investigadores más cercanos a la actualidad como Imberty (1993) quien expone entre otros aspectos, las estrategias que adopta el oyente al enfrentarse a la audición de música contemporánea a modo de pistas o huellas, event hierarchies; una especie de referencias auditivas de carácter musical que el oyente tiene necesidad cognitiva de encontrar en el discurso musical contemporáneo. En esta línea cabe citar a Serafine (1988), autora pionera en el desarrollo de la idea del mentalismo como fundamento de la experiencia musical.

Adessi (2005) realiza una investigación sobre la percepción de la forma en la música post-tonal por parte de músicos y no músicos, los cuales se enfrentaron a varias audiciones de una obra y, en tiempo real, tenían que intentar percibir la estructura general. No existían diferencias significativas entre ambos grupos pero cuando se les preguntaba sobre las estrategias utilizadas, los músicos denotaron unos procedimientos mucho más específicos y técnicos, mientras que parámetros como la 
intensidad o el timbre fueron utilizados por los no músicos. Espinosa (2007) a través de un proyecto de investigación titulado La escucha reducida. Un estudio exploratorio para la calidad auditiva, llega a la conclusión de que la escucha reducida favorece la comprensión y práctica de obras de la estética musical contemporánea. Ordoñana (2011) en su tesis doctoral hace un acercamiento a la música contemporánea de características atonales desde la percepción, aplicado todo ello a un contexto musical especializado como es el del Conservatorio de Música. Laucirica et al. (2012), destaca por su trabajo sobre la música contemporánea atonal desde la percepción, realizando interesantes aportaciones sobre la música atonal en la educación, concretamente en éste profundiza en la audición, cognición y emoción en la interpretación de obras atonales por parte de alumnos que cursan estudios superiores de música. Vidal y Vidalot (2013) también estudian el efecto de la música reducida a estudiantes del Grado de Educación Infantil y concluyen que es necesario apropiarse de un discurso para comprender y referirse al arte sonoro.

Atendiendo a lo citado anteriormente, el nivel educativo de la Educación Secundaria Obligatoria, concretamente en España, está bastante carente de bibliografía especializada en didáctica de la música contemporánea, de hecho Muñoz (2001:27) resalta el hecho de que la música contemporánea no está naturalmente tratada en la educación:

[...] ¿ cómo no enseñar la música de su tiempo a los protagonistas de este siglo?, ¿ por qué caer en el consabido escollo de preparar a las personas de hoy únicamente con las herramientas de ayer? [...] si los niños de hoy ya conocen los escritos de los autores vivos de su tiempo, si contemplan con interés las exposiciones de pintura de su siglo, démosles una formación integral de la música actual para que igualmente puedan disfrutarla y conformar un espíritu crítico.

A través de este trabajo se ha tratado de ofrecer una propuesta metodológica para la enseñanza de la música contemporánea para que los alumnos la comprendan desde un punto de vista vivencial.

El concepto de música contemporánea, referido a la música clásica contemporánea de características atonales es difícil de sistematizar, pero en cambio, resulta mucho más fácil de intuir y reconocer por sus peculiaridades estilísticas (Marco, 2007).

Para diseñar la propuesta metodológica encaminada a la comprensión de la música contemporánea, se optó por realizar un acercamiento vivencial a ésta, a través de un elemento esencial en todo proceso musical: la audición activa en diferentes formatos.

La audición y concretamente la audición activa es una fórmula factible, para cualquier estética musical e idónea para el alumnado de educación secundaria, además de beneficiosa desde un punto de vista pedagógico. Con este acercamiento vivencial a la música contemporánea, se pretendía que al realizar una audición o al asistir a un concierto, que el alumnado supiera, siguiendo en la línea de Marco (2007) intuirla, reconocerla como estética contemporánea y que entendiera, comprendiera e incluso lograra extraer de ella elementos habitualmente recurrentes en los diferentes estilos compositivos contemporáneos, más que la diferenciación entre éstos.

Atendiendo a datos empíricos extraídos de las obras citadas anteriormente existe una problemática por parte del alumnado a la hora de enfrentarse a la música contemporánea:

- Por una parte la enculturación tonal a la que está sometida una persona desde que nace, ya que el modelo tonal predomina en la mayor parte de las manifestaciones musicales que nos rodean, elegidas libremente por el oyente o impuestas. En la actualidad autores como Ordoñana et al. (2006), hablan de la presencia casi exclusiva de la música tonal en la educación y de la enculturación tonal a la que estamos sometidos. Laucirica et al. (2012: 3-4), también se refieren a esta problemática en su investigación diciendo:

La intensa aculturación tonal que vivencia cualquier ser humano occidental con o sin formación musical, por el simple contacto desde sus primeros años de vida con la estructura musical que configura la jerarquía tonal es el principal componente de carácter cognitivo, [...] La enculturación musical se produce cuando en los primeros años de vida, el ser humano occidental sufre unos procesos de asimilación e integración que le conducen a la comprensión de la música tonal.

Laucirica et al.(2012) citan en su investigación a Imberty (1969) quien también trató entre otros aspectos, la problemática de la comprensión de la música contemporánea, aludiendo a la enculturación del ser humano como una de las principales causas de su rechazo hacia este tipo de 
música. Este proceso de enculturación provoca finalmente un gusto por un determinado tipo de música u otro. Por ello, el componente social es otro factor que aún siendo consecuencia del anterior, provoca el rechazo o no comprensión de la música clásica contemporánea. A ello añadimos, acercándonos al mundo adolescente, el enorme poder de persuasión auditiva que tienen los medios de comunicación, el mercado musical, y la influencia de la música popular.

- La otra razón que provocaría la no comprensión o el rechazo hacia este tipo de música por parte del alumnado, podría venir de la mano del propio sector docente; es imprescindible una buena formación y saber qué se está enseñando. Ordoñana et al. (2006) explican que para poder apreciar la nueva música es necesario conocerla y en el caso del profesorado se ha debido de producir un paso más complejo, saber enseñarla.

Palacios (1994: 3), expone la importancia de la preparación docente y aunque se refiere a la enseñanza de la música en general, sus comentarios pueden aplicarse perfectamente a la enseñanza para la apreciación de la música clásica contemporánea:

\begin{abstract}
¿Cómo conseguir motivar a nuestros alumnos?. Veamos lo que nos dice D. Kavalevski al respecto: "Ninguna ley didáctica puede reemplazar la inteligencia, el tacto y el talento docente; él debe suscitar en ellos el deseo de leer y oír lo que nunca han escuchado" [...] Aunque esto no es fácil (aparentemente lo parece) deberá hacer un esfuerzo para conocer perfectamente las obras que quiere mostrar, estudiar sus aspectos esenciales, las posibilidades que tienen [...] Con un profesorado competente y preparado, la motivación pasa a ser una simple célula de arranque.
\end{abstract}

Trallero (2008) cree que no es nueva la idea de que en la educación el sonido debería preceder al símbolo. Sus orígenes se encuentran entre otras, en las teorías del aprendizaje propuestas por Pestalozzi y retomadas por Mason al formular las orientaciones para el currículo de música de las escuelas de Boston que postulaba, entre otros puntos, que hay que: enseñar sonidos antes que signos y provocar situaciones de aprendizaje en las que los estudiantes observen y descubran escuchando e imitando, en lugar de explicar conceptos.

Todo proceso de educación musical debería partir de la práctica, esto es, del desarrollo de capacidades relacionadas con la audición, la interpretación y la composición. Paralelamente, y como resultado del mismo proceso de aprendizaje, el alumno irá interiorizando construyendo un vocabulario que le permita expresarse musicalmente y comprender lo que escucha. Corrientes de apreciación musical de principios del s. XX ya destacaban la necesidad de una audición guiada, y en la década de 1970 se dio mucho énfasis a las competencias de audición. Los niños necesitan realmente tener competencias de audición bien desarrolladas para apreciar la música de modo efectivo Haack (1992). Son conocidos a nivel general autores pioneros en el tema de la escucha/audición como Copland (1939), quien entre otros aspectos resalta el valor de la escucha y los diferentes tipos de oyente que pueden existir según su formación. En esta línea cabe incluir a Zamacois (1975) o Swanwick (1988).

Escuchar y oír música, son conceptos que en contextos no académicos, se utilizan como sinónimos. No obstante, escuchar supone un acto de atención en lo que está sonando y se activan consecuentemente una serie de respuestas físicas, afectivas e intelectuales. Es un proceso cognitivo relacionado a su vez con las creencias socioculturales. El papel del oyente y su percepción, independientemente de seguir unas teorías u otras, es imprescindible en cualquier caso. Supone el fin de un proceso en cadena que comenzó con la composición y acaba en él. Su papel es vital, como expone Palacios (2001:97-98):

La responsabilidad de quien interpreta es grande: edifica en sonidos los planos escritos por el arquitecto músico. La responsabilidad de quien escucha también es grande: completa, termina, justifica la obra. Quien interpreta recrea; quien escucha participa de la obra, la recompone en su memoria, la reconstruye en su interior [...] Escuchar es volver a componer pero al revés; es el trabajo inverso al del compositor, también es un acto de creación [...] la creación de la obra en su interior.

La música es ante todo un fenómeno perceptivo, cada oyente escucha u oye de una forma, pues está condicionado tanto por el propio estímulo auditivo y sus peculiaridades, como por sus propios elementos fisiológicos y psicológicos, los cuales son determinantes. La audición en cualquier contexto educativo musical es imprescindible. Marín (2003) afirma que se debe educar el sentido 
auditivo de los alumnos para que sean capaces de realizar juicios razonados, olvidando en la medida de lo posible las respuestas relacionadas con el gusto (me gusta o no me gusta). Todo tiene un por qué y el verdadero valor de la audición aparece cuando se es capaz como oyente de apreciar lo que hemos escuchado más allá de la simple mirada.

\section{OBJETIVOS Y METODOLOGÍA}

Los objetivos principales de esta investigación son:

- Contrastar dos metodologías de aprendizaje para la comprensión de la música contemporánea: una consistente en la clase magistral y la otra en una metodología más vivencial y experimental, basada en la audición.

- Comprobar qué método resulta más idóneo para la comprensión ${ }^{2}$ de la música contemporánea en la Educación Secundaria Obligatoria.

Cabría añadir un tercer objetivo, que como tal no pertenece al diseño de la investigación, pero de forma intrínseca está presente durante todo su desarrollo pues es un objetivo del docenteinvestigador de este trabajo y a su vez relacionado con los objetivos de las Unidades Didácticas aplicadas al grupo experimental y control:

- Trabajar la música contemporánea en el aula de secundaria.

Al aplicar y contrastar dos metodologías, como se acaba de exponer, se ha requerido diseñarlas y desarrollarlas a través de unas Unidades Didácticas las cuales por igual tenían los siguientes objetivos específicos ${ }^{3}$, relacionados obviamente con los generales de la investigación:

- Comprender la estética y contexto histórico de la música contemporánea para formarse una opinión personal y crítica desde el respeto y la comprensión.

- Comentar desde la reflexión y el juicio crítico audiciones de música contemporánea.

- Entender la atonalidad como una característica presente en algunas corrientes de música contemporánea.

Para alcanzar los objetivos propuestos se ha seguido una metodología cuasi-experimental, con dos grupos intactos pertenecientes al nivel de $3^{\circ}$ de la ESO en la materia de música. La muestra contaba con un total de $n=41$ alumnos. Se ha realizado por tanto una comparativa cuantitativa $y$ cualitativa, ante la aplicación de dos metodologías diferenciadas: una metodología tradicional: la clase magistral, al grupo control y una metodología experimental y vivencial basada en la audición, al grupo experimental.

La metodología cuasi-experimental es con frecuencia recurrida dentro del ámbito educativo. A través de las técnicas de recogida de datos cuantitativos y cualitativos utilizados como son el cuestionario pre y post-test, la encuesta de valoración, el cuestionario de perfil de la muestra y el cuaderno de campo, se ha pretendido ir más allá de la mera descripción del fenómeno estudiado, tratando de llegar a la comprensión e interpretación ${ }^{4}$, aunque cabe resaltar que la parte cualitativa del experimento ha permitido alcanzar óptimamente este objetivo.

Dada la no aleatorización de la muestra, no ha sido posible establecer de forma exacta la equivalencia inicial de los grupos, como ocurre en los diseños experimentales. Cook y Campbell (1986:142), consideran los cuasi-experimentos como una alternativa a los experimentos de asignación aleatoria, en aquellas situaciones sociales donde se carece de pleno control experimental, "los cuasiexperimentos son como experimentos de asignación aleatoria en todos los aspectos, excepto en que no se puede presumir que los diversos grupos de tratamiento sean inicialmente equivalentes dentro de los límites del error muestral". Ante esto se ha pretendido realizar la investigación con el máximo rigor metodológico.

En primer lugar, se ha procedido con la metodología cuantitativa y un tratamiento estadístico de las preguntas del cuestionario diseñadas para tal efecto, con el programa IBM SPSS stadistics versión 19. A continuación se ha realizado un acercamiento metodológico cualitativo de éste, complementado con el cuestionario acerca del perfil de la muestra, la encuesta de valoración y el cuaderno de campo del profesor. Todos los datos fueron triangulados, para así enriquecer la comprensión e interpretación de éstos. 
El planteamiento del problema parte de preguntarse como docente qué metodología resultará más idónea para la comprensión de la música contemporánea por parte del alumnado de $3^{\circ}$ de la ESO. Para ello y empezando con la fase cuantitativa, se ha pasado a cada uno de los grupos un pretest, y a continuación se ha comprobado el grado de ajuste a la normalidad gausiana en la distribución de la muestra, a través de la prueba Kolmogorov-Smirnov. Posteriormente, con el objeto de denotar si existen diferencias significativas entre ambos grupos se ha pasado la prueba, en este caso no paramétrica, para muestras independientes $U$ de Mann-Whitney. Como se podrá ver en posteriores puntos de este trabajo, se ha tenido que aplicar esta prueba porque la muestra no se ajustaba a una distribución normal.

Posteriormente y teniendo en cuenta los resultados del pre-test, se realizó la intervención didáctica, consistente como se ha dicho anteriormente, en la aplicación de una metodología experimental basada en la audición de música contemporánea, al grupo experimental y otra metodología basada en la clase magistral, al grupo control. Se ha diseñado, por tanto, una Unidad Didáctica para cada grupo, con distinto enfoque metodológico pero con la misma duración y trabajando los mismos contenidos, los cuales a su vez parten del currículo oficial.

Una vez finalizada la aplicación de la Unidad Didáctica, a ambos grupos se les ha realizado un post-test. Los resultados pre-test y post-test se han contrastado intra-grupo e inter-grupo. Concretamente la comparación de los datos post-test se ha realizado estadísticamente a través de la aplicación de la prueba no paramétrica $U$ de Mann-Whitney, que comparará los resultados de ambos grupos, para denotar si existen diferencias significativas después de la aplicación didáctica. También se les ha pasado la prueba estadística no paramétrica de los rangos con signo de Wilcoxon para muestras relacionadas, para denotar si existen diferencias significativas intra-grupo entre el pre-test y post-test.

Junto a estos datos y como se ha mencionado anteriormente, cabe añadir también los obtenidos a través de la fase cualitativa de la experiencia, procedentes de un acercamiento metodológico basado en la interpretación y descripción de las preguntas del cuestionario, haciendo especial hincapié en las de tipología abierta, en la encuesta acerca del perfil de la muestra y en la encuesta de valoración. Se han recogido todas las respuestas de las preguntas abiertas del pre-test y post-test de cada alumno, a continuación se ha procedido a la comparación primero entre el propio alumno antes y después de la intervención didáctica y posteriormente se ha realizado una comparación entre ambos grupos, previa categorización de las respuestas.

Por otra parte, a través de la encuesta de valoración se ha procedido a comparar el gusto por la música contemporánea de cada uno de los alumnos antes y después de la intervención didáctica, así como la comparación de este aspecto entre grupos. Además, a través de la encuesta, quedan reflejadas las opiniones de los alumnos acerca de su grado de satisfacción en la metodología empleada en su clase y su percepción sobre el grado de comprensión de los contenidos tratados en la Unidad Didáctica. El análisis y triangulación de estos datos permitirá posteriormente aportar conclusiones y propuestas para trabajos futuros.

\section{CARACTERÍSTICAS DE LA METODOLOGÍA APLICADA AL GRUPO EXPERIMENTAL Y AL GRUPO CONTROL}

\section{Metodología de la Unidad Didáctica del grupo Experimental}

Para conseguir que la audición de música contemporánea resultara un proceso fructífero y consciente por parte del alumno, la Unidad Didáctica de la metodología experiencial se diseñó de forma constructivista y progresiva.

En lo que respecta a los contenidos, éstos se secuenciaron contextual e históricamente, separando el siglo XX en dos mitades y tratando los diferentes estilos y estéticas musicales interrelacionadas con su contexto histórico, político, social y artístico. No obstante la atonalidad y su comprensión, no sólo como un movimiento o estilo compositivo concreto, sino como una característica bastante recurrente en la música clásica contemporánea del XX y XXI fue uno de los conceptos en los que más se ahondó. A través de 8 sesiones se intentó que la audición en diferentes 
formatos fuera el eje vertebrador de la Unidad Didáctica. Los alumnos a través de un cuaderno ${ }^{5}$ diseñado especialmente para el trabajo de esta Unidad Didáctica debían elaborar sus propios apuntes a través de los aspectos teóricos que se iban introduciendo en el tema expuestos por el profesor, a partir de obras de arte representativas, textos de la época o lectura de textos, además de realizar sus propias reflexiones en los lugares habilitados para ello, y siempre desde una perspectiva cooperativa entre ellos. El diálogo y las reflexiones conjuntas guiadas por el profesor eran la clave para ir elaborando los contenidos. Junto a esto, tenían que realizar los ejercicios programados en él, todos ellos basados en la audición de diferentes obras representativas de la música contemporánea y tratados desde diferentes perspectivas.

Las audiciones de la Unidad Didáctica se diseñaron para ser escuchadas a través del seguimiento de musicogramas y otras fueron audiciones guiadas, siguiendo determinados parámetros del sonido y contestando determinadas cuestiones. Se realizaron también audiciones libres en cuanto a descripción e interpretación, se propusieron audiciones utilizando otros tipos de lenguajes extra musicales, audiciones por grupos, contrastadas, visualización de obras musicales contemporáneas, audiciones musicales con danza, con imágenes, descriptivas libres, descriptivas guiadas a través de preguntas discriminatorias en algún aspecto cualitativo del sonido, audición con pintura, creación propia de musicogramas partiendo de una propuesta auditiva y audición con notación no convencional. Con este formato se pretendía de alguna manera entrenar el oído del alumno y que éste experimentara una escucha activa y sensible, que experimentara también a través del grupo, reforzando su vocabulario y su capacidad de percepción y comprensión a medida que transcurría la Unidad Didáctica y las diferentes actividades diseñadas al respecto. Al final de ésta entre otros aspectos, y como se ha comentado con anterioridad, debía de tener claro el concepto de atonalidad en la música clásica contemporánea y la sensación auditiva que ésta provoca, sabiendo utilizar un vocabulario específico o al menos acertado en cuanto a conceptos para saber describirla e intuirla. La comprensión del contexto histórico del momento también era un importante objetivo que debía comprender e ir progresivamente asimilando a través de la secuenciación de los contenidos de la Unidad Didáctica, para así tener una visión más amplia y reforzada de este tipo de estética musical.

En la $1^{a}$ sesión se trató de hacer una breve exposición del proyecto que se iba a llevar a cabo, y se pasó el cuestionario del perfil y el pre-test. Esta sesión se dedica exclusivamente a estas dos actividades; cabe comentar que las audiciones del pre-test, debido a sus características estilísticas, causaron bastante impacto y desconcierto al grupo; costó bastante encauzar al conjunto después de cada audición, pues se hicieron excesivos comentarios que provocaron cierta desconcentración en el pre-test.

La $2^{a}$ sesión se inició con un bombardeo auditivo de diferentes ejemplos escogidos de música contemporánea (obras de Stockhausen, de Webern, de Schoenberg, etc.) ante los cuales se pidió sin más, una reflexión escrita sobre la primera impresión al escuchar esta estética musical. A continuación se procedió a la proyección del contexto histórico artístico de la época, destacando entre estas proyecciones esquemas cronológicos y estilísticos de finales del XIX y primera mitad del XX, con los compositores representativos y obras de arte paralelas en el tiempo, todo ello con la pretensión de que el alumno fuera anotando en su cuaderno los elementos esenciales que se estaban trabajando. La tercera actividad de esta sesión consistió en un breve debate conjunto sobre el gusto por este tipo de estética musical y artística en la que se estaban empezando a sumergir.

La impresión por parte del profesor fue mejorando a medida en que se iba desarrollando la sesión, pues se inició con bastante descontrol al enfrentarse sin más en los primeros minutos a varias audiciones seguidas de música contemporánea, y los alumnos se encontraban un tanto desconcentrados y les costaba expresarse en la actividad reflexiva. El debate final sobre el gusto inicial por esta estética musical fue más fructífero, más pausado y organizado. La opinión no obstante hacia esta música era totalmente negativa y cerrada por parte del conjunto.

En la $3^{a}$ sesión se presentó de forma muy generalizada una proyección con las características básicas del periodo clásico-romántico en lo referente a aspectos como la melodía, la armonía, la textura, la estructura, la instrumentación, los ritmos etc. y se propuso escuchar una pieza de la época clásica, concretamente el inicio de la Sinfonía $n^{\circ} 40$ en Sol M. de W. A Mozart. A continuación se 
propuso un fragmento de la obra Pierrot Lunaire de A. Schoenberg. Partiendo de una plantilla preestablecida en la que aparecían los aspectos melódicos rítmicos etc., como se ha explicado anteriormente, los alumnos debían comparar lo que escuchaban con lo que en la época clásicaromántica se solía hacer escribiendo sus reflexiones en el cuaderno habilitado para ello.

Después de introducir el concepto de la atonalidad se propuso de nuevo una audición de una pieza la época atonal expresionista, unos segundos de otra sección del Pierrot Lunaire de A. Schoenberg. La forma de trabajar la audición de esta pieza fue por discriminación auditiva de diferentes elementos; cada vez que se escuchaba esta pieza musical debían centrar la atención en una cualidad del sonido o elemento de la música determinado y reflexionar por escrito sobre ello.

Ya en esta sesión se denotó más voluntad por parte del grupo de sacar el máximo partido a los ejercicios de audición; daba la sensación de que se estaban acostumbrando a trabajar de esta forma más práctica y autónoma además de estar adaptándose a la audiciones de música contemporánea.

En la $4^{a}$ sesión se proyectó el contexto histórico de la segunda mitad del siglo XX en la misma línea que el anterior; $1^{\circ}$ se introdujo el concepto de dodecafonismo, se explicó la técnica compositiva; después se realizó una audición guiada a través de un musicograma, de una pieza musical perteneciente al serialismo integral, concretamente un fragmento del Cuarteto de cuerda op. 28 del compositor A. Webern. Para la creación del musicograma el profesor ha utilizado signos tipo-morfológicos del sonido fusionados con otros signos más tradicionales dentro del lenguaje musical. Se observó que la mayor parte de los alumnos fueron capaces de seguirlo con este tipo de signos. Se les propuso 3 veces la audición de la pieza ya que ésta tenía una duración de 30 segundos.

A continuación se propuso otra actividad consistente en realizar un dibujo libre a partir de una audición propuesta. Concretamente la pieza elegida era de O. Messiaen, Des canyons aux etoiles. Se escucharon los cuatro primeros minutos y se dieron ciertas pautas para realizar el dibujo centrados en aspectos melódicos y tímbricos. Luego debían reflexionar por escrito sobre lo que habían pintado. La obra de $\mathrm{O}$. Messiaen estaba inspirada en un paisaje real y se pretendía posteriormente comparar los dibujos de los alumnos con el contexto en el que realmente estaba inspirada; obviamente se tuvo en cuenta que nunca existe una correspondencia exacta entre el lenguaje musical y el escrito, no obstante se pretendía únicamente que captaran a través de sus dibujos y en especial de los tonos elegidos, la esencia de lo que la pieza musical simbolizaba.

Esta actividad se acogió con mucho interés y agrado, era bastante diferente a todo lo realizado anteriormente. A la hora de realizar e intentar plasmar en la hoja a través de la forma y el color los aspectos auditivos que se les pedía discriminar, se produjo bastante desconcierto dada la inexperiencia. Se pudo apreciar por parte del profesor, que la actitud era totalmente receptiva e involucrada.

La quinta sesión comenzó con una introducción a la notación no convencional en la música contemporánea. Para ello, se escuchó en primer lugar la audición de la pieza vocal Stripsody de Caterine Barberian. Los alumnos debían inventarse una notación para los primeros segundos de la obra. Cabe comentar el revuelo y comentarios humorísticos acerca de ésta, la cual impactó sonora y luego visualmente al grupo. Después se volvió a realizar la audición de la pieza, esta vez visualizando la partitura para que intentaran seguirla y observaran el tipo de notación utilizada. Para finalizar el ejercicio se volvió a escuchar Stripsody pero esta vez visualizando la interpretación. Lo que se pretendía, era tratar conceptos como la no convencionalidad de la notación y del tratamiento de la voz, pero sobre todo se pretendía que reflexionaran acerca de la música contemporánea y el público, sobre si los conciertos convencionales eran el formato idóneo para este tipo de música y sobre cómo comprendían mejor este tipo de música contemporánea, desde la audición sin ver la interpretación o visualizando la interpretación.

La sesión $\mathrm{n}^{\circ}$ 6, presentó en su inicio una obra de P. Boulez, Le marteau sans maitre, $\mathrm{n}^{\mathrm{o}}$ IX, 1952. La escucha de esta pieza debía realizarse siguiendo una plantilla la cual contenía diversas características afines y no afines a la audición. Cada vez que se leía una característica debían de concentrar la atención en ese elemento en concreto y reflexionar sobre ello, para poder marcar la opción correcta. Los elementos más recurridos para discriminar fueron aspectos relacionados con la 
voz y su tratamiento, el timbre y la melodía y la sensación auditiva de la atonalidad.

La siguiente actividad consistió en realizar una audición por grupos. Se procedió a formarlos y a continuación se propusieron las pautas del ejercicio, consistente en reflexionar conjuntamente sobre la audición de dos piezas para orquesta y comentar los aspectos requeridos en la plantilla proporcionada en el cuaderno. La primera audición que se realizó fue la de la Sinfonía $n^{o} 9$ de Bruckner la cual debían comparar con la pieza orquestal Notation VII, de P. Boulez. Se trataba de escuchar una obra contemporánea para orquesta, pues hasta ahora todo habían sido propuestas instrumentales reducidas de índole camerística, y a través del comentario conjunto intentar describir libremente cualquier aspecto sobre todo centrándose en el tratamiento orquestal.

Se pudo denotar por parte del docente una actitud muy positiva y cada vez más abierta a este tipo de música; los comentarios y reflexiones cada vez eran más fluidos, ya no costaban tanto y el diálogo era más abierto, por el vocabulario que poco a poco estaban adquiriendo.

En la sesión $n^{\circ} 7$, se trató el concepto de aleatoriedad aplicado a la composición; se realizó una audición guiada por el profesor, de un fragmento de una pieza para piano preparado de J. Cage. Posteriormente se introdujo el concepto de música textural, y para ejemplificarlo se propuso la audición y visualización posterior de una pieza del compositor G. Crumb. Se pretendía que reconocieran el tratamiento textural del sonido, el tratamiento no convencional de los instrumentos y que reflexionaran a partir de la audición, sobre qué les había gustado más: visualizar la obra o por el contrario únicamente escucharla. La sesión finalizó con la realización de una serie de actividades de recopilación acerca de aspectos conceptuales tratados en la Unidad Didáctica.

Sesión $\mathrm{n}^{\circ}$ 8: Se pasó el post-test y la encuesta de valoración. Cabe comentar que la actitud de mayor determinación y apertura a esta música fue progresivamente mejorando a lo largo de las sesiones a medida en que se iba conociendo mejor, de hecho el post-test y la encuesta de valoración se hicieron con normalidad y actitud positiva a diferencia de lo que había ocurrido en la primera sesión con el pre-test.

\section{Metodología de la Unidad Didáctica del grupo Control}

El diseño de la Unidad Didáctica del grupo control fue también estructurado desde una perspectiva constructivista y progresiva en cuanto al tratamiento de los contenidos. Ambas metodologías trabajaron los mismos contenidos, la diferencia estaba en que en el grupo control estos contenidos eran presentados desde una perspectiva eminentemente teórica. Los alumnos disponían de un dossier previamente elaborado por el docente; a diferencia del grupo experimental, éstos no debían elaborar los conceptos a través de la experiencia. Los contenidos de la Unidad Didáctica estaban secuenciados de forma progresiva y cronológica atendiendo a las diferentes vanguardias del siglo XX. Las audiciones, que eran las mismas que las presentadas al grupo experimental, eran explicadas por parte del profesor previamente o durante la misma, desde un punto de vista teórico; se presentaba la audición y se resaltaban las características que la definían auditivamente. Los alumnos no eran directamente partícipes de la construcción de su propio conocimiento a través de una audición activa o sugerente, pues los contenidos ya estaban desarrollados en el dossier; no obstante la peculiaridad de la estética de las audiciones fue un elemento que permitió ampliar los contenidos por la curiosidad y respuesta intelectual de los alumnos del grupo control hacia este tipo de música, enfocado todo siempre desde un punto de vista magistral; el alumno preguntaba el profesor respondía.

\section{ESTRUCTURA Y CRITERIOS DE ELABORACIÓN DEL CUESTIONARIO}

Como se ha explicado anteriormente, para poder comparar ambas metodologías, la tradicional centrada en la clase magistral y la experiencial basada en la audición activa, se elaboró un cuestionario pre y post-test. Dado el tipo de alumnado que formaba la muestra, la necesidad de recoger información y la escasez de tiempo, se optó por aunar en un único documento además del cuestionario pre y post test, un cuestionario acerca del perfil de la muestra y una encuesta de valoración. 
Por una parte, el cuestionario pre-test y post-test que se ha utilizado, está diseñado, para recoger datos tanto cuantitativos como cualitativos. Se ha realizado en base a los contenidos que se trabajan en las Unidades Didácticas de ambas metodologías partiendo del nivel del alumnado de $3^{\circ}$ de la ESO. Se hizo una primera propuesta de cuestionario, la cual se pidió validar a expertos en la materia. Consecuentemente y después de analizar las diferentes observaciones por parte de éstos, se volvió a diseñar el definitivo, el cual tenía la siguiente estructura:

$1^{\text {a }}$ parte: INFORMATIVA: Recoge datos acerca del perfil de la muestra. Variable independiente: edad, gustos musicales, conocimientos musicales previos, sexo, nota asignatura de música, gusto hacia la asignatura.

$2^{a}$ parte: PRE- TEST y POST-TEST: Son 20 preguntas las cuales se valoraron de 0 a 10 . De este total de preguntas 14 eran cuantitativas, con múltiple respuesta de identificación y su contenido estaba basado en variables de índole cualitativa (timbres, texturas, tempo, contornos melódicos, conceptos, etc.) y se valoraron cuantitativamente, desde un punto de vista estadístico. Por otra parte, las 6 preguntas restantes del cuestionario eran de índole cualitativa y diseñadas como preguntas abiertas. El tratamiento de análisis fue cualitativo. En primer lugar se procedió al tratamiento estadístico de las de tipología cuantitativa. Posteriormente se realizó un análisis cualitativo en general del cuestionario haciendo especial hincapié en las preguntas abiertas del documento, realizando además una comparación tanto intra-grupo como inter-grupo.

$3^{\mathrm{a}}$ parte: ENCUESTA DE VALORACIÓN: Formada por 3 preguntas. La primera de ellas era una pregunta abierta de opinión sobre el gusto por la música contemporánea escuchada en el pre y post-test $^{6}$. La segunda era una pregunta de opinión acerca de la metodología empleada en el grupo y la tercera pregunta estaba referida a la comprensión de los contenidos de la Unidad Didáctica, a la cual tenía que responder los alumnos a través de una escala Likert.

En general el diseño de las preguntas de la segunda parte del cuestionario se ha basado en varios aspectos que a continuación se detallan:

PREGUNTAS $\mathrm{N}^{\circ} 1,2$ y 3 . Pregunta $\mathrm{n}^{\circ} 1$ : Vas a escuchar una pieza representativa de la música atonal del S. XX: a. ¿Cómo definirías la melodía de esta audición?; b. Dibuja la melodía.

A través de esta cuestión se pretendía que el alumno partiendo de la audición discriminara un elemento básico de la música, la melodía, y a partir de la reflexión intentara describir con sus propias palabras qué estaba escuchando respecto a ésta, en todos los aspectos. La pretensión era comparar la respuesta del pre-test y post-test y denotar si existía cierto grado de mejoría en cuanto al uso de terminología, en la utilización de un vocabulario específico y adecuado a las circunstancias. En la segunda parte de esta pregunta se pedía al alumno que trazara instintivamente el contorno melódico escuchado. La idea de la plasmación gráfica ha sido utilizada para que el alumno se fuera familiarizando con la notación no convencional, y la plasmación no convencional del sonido. Para ello, se propuso la obra de A. Webern Tres rimas para voz, violín, clarinete y clarinete bajo, Op. 17, III. Esta obra resultaba interesante por ser un ejemplo de música serial dodecafónica, con un resultado auditivo y melódico claramente atonal, con la utilización de una instrumentación reducida (voz, violín, clarinete y clarinete bajo) que permitía discriminar bien qué timbre/s realizaban la melodía además de un tratamiento característico de la voz y una muy breve duración, concretamente 36 segundos.

Para la pregunta $n^{\circ} 2$ : ¿Qué célula melódico-rítmica, de las siguientes grafías no convencionales que se proponen a continuación, crees que se da en más ocasiones a lo largo de la audición?, se propuso la misma audición que en la cuestión $\mathrm{n}^{\circ} 1$; no obstante, ahora planteada desde una perspectiva diferente. Se pretendía que el alumno a partir de varias propuestas tipo-morfológicas alusivas al contorno melódico, eligiera la opción correcta, tal y como se aprecia en la Figura 1: 


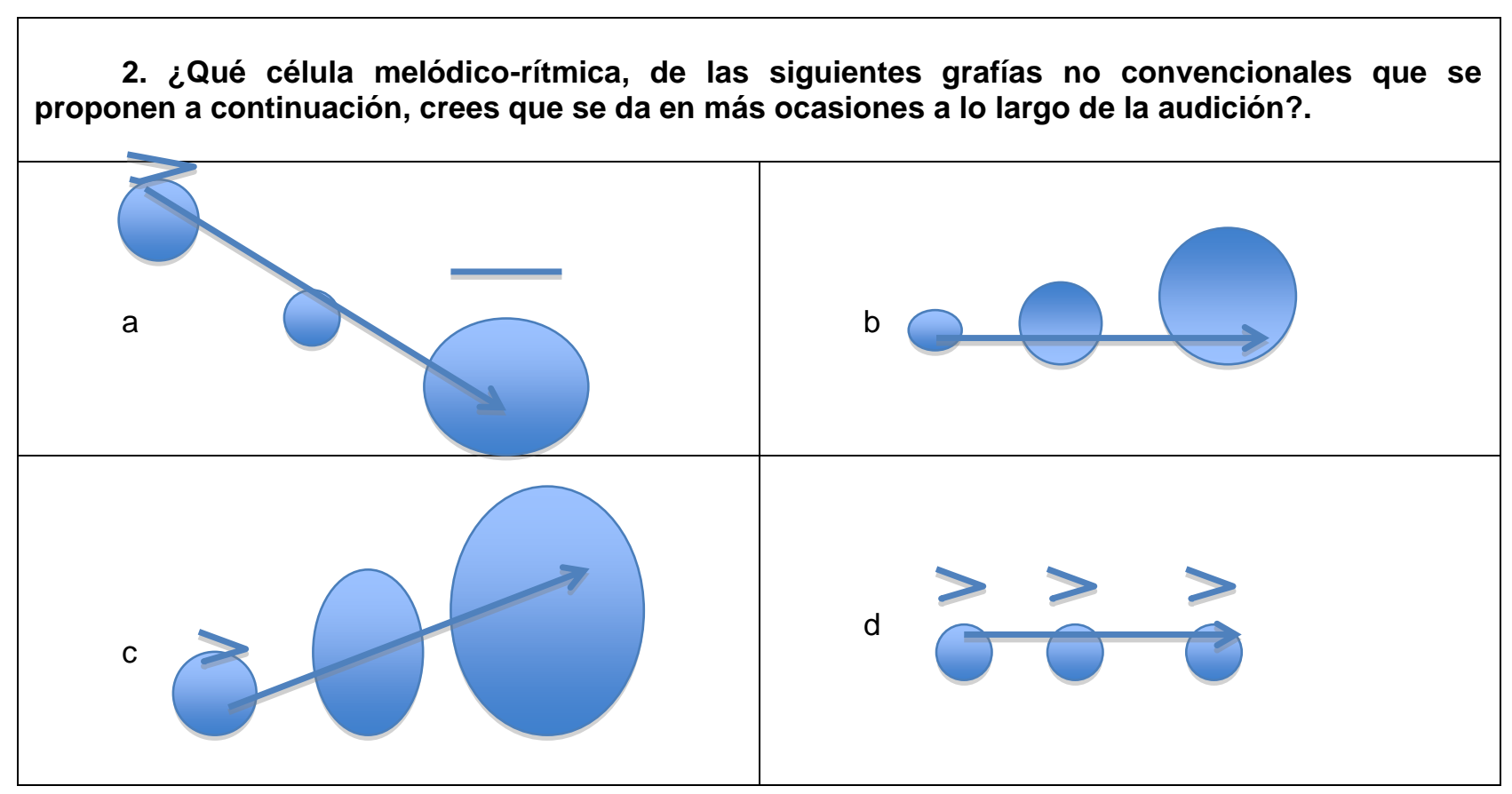

Figura 1. ¿Qué célula melódico-rítmica, de las siguientes grafías no convencionales, crees que se da en más ocasiones a lo largo de la audición?

El planteamiento de esta cuestión pretendía seguir la teoría de la escucha reducida, propuesta por Schaeffer (1988) y Chion (1990). Si en la anterior pregunta la misma música debía ser descrita a nivel del contorno melódico y de forma libre tratando cualquier cualidad dentro de la melodía, ahora se planteaba lo contrario. Se proponían cuatro ejemplos tipo morfológicos alusivos a una célula melódico-rítmica constante a lo largo de la audición y en donde visualmente quedaban resaltados aspectos como la altura y la dinámica, debiendo escoger el correcto.

En la $3^{\text {a }}$ cuestión, se proponían varios ejemplos gráficos no convencionales alusivos también al contorno melódico, junto con una definición generalizada de la melodía. Se pretendía que el alumno se fuera familiarizando con la plasmación no convencional de cualquier cualidad del sonido:

\section{3. ¿Cómo definirías las melodías escuchadas?.}

a. Melodías onduladas y claramente estructuradas.

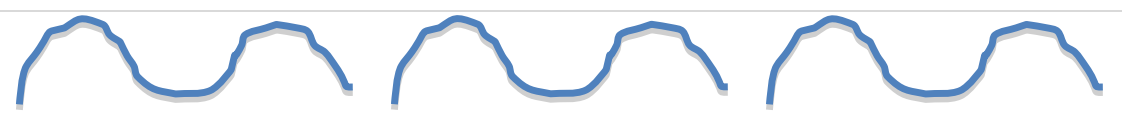

b. Lineales, infinitas y sin puntos de tensión ó relajación melódica.

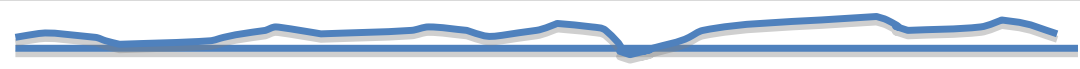

c. Melodías de grandes saltos interválicos.

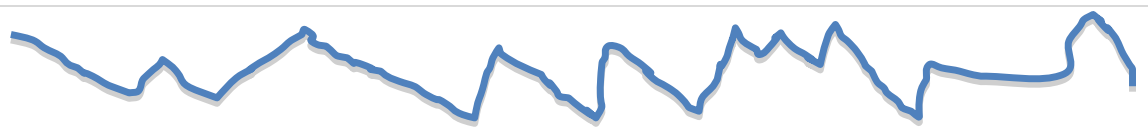


Figura 2. ¿Cómo definirías las melodías escuchadas?

PREGUNTA $\mathrm{N}^{\circ}$ 4, 5, 6 y 7. Para estas cuatro cuestiones se ha seleccionado la obra de T. Hosokawa Vertical Songs I for flute solo. Esta pieza resulta interesante por varios aspectos: el tratamiento no convencional del instrumento, la flauta, además de porque está inspirada en la escritura japonesa y presenta muchos momentos de silencio, a modo de vacíos, con una gran expresividad, por lo que también resultaba bastante desconcertante auditivamente hablando. La atonalidad impera en la pieza junto con una clara falta de estructura, al menos a priori y en el primer contacto auditivo, así lo parece; obviamente un análisis más profundo conllevaría a poder analizar su posible estructura, pero este contexto académico no era el adecuado para este tipo de análisis.

La pretensión en la pregunta $n^{\circ} 4$ (¿qué timbre está sonando?), era la discriminación tímbrica de la flauta, de un instrumento que sonaba de forma no convencional. Se partía de un elemento en concreto, el timbre, que el alumno debía de reconocer. Lo mismo ocurría en la pregunta $\mathrm{n}^{\circ} 5$ (¿qué función crees que tiene el silencio dentro del discurso sonoro audición?), se pedía al alumno que reflexionara acerca de la función del silencio en esta pieza musical.

La pregunta $n^{\circ} 6$, (¿con qué imagen de las que se proponen a continuación, asociarías la siguiente audición? y ¿por qué?), a diferencia de las anteriores era abierta y el alumno debía de asociar la imagen a la propuesta auditiva y explicar el porqué de la relación. La primera imagen, era caligrafía japonesa; la energía en el trazo de las líneas y los vacíos en blanco para separarlas rompían con el espacio, al igual que el sonido enérgico e impulsivo de la flauta lo hacía con el silencio. La otra imagen, podía dar lugar a la confusión, pues era una obra expresionista abstracta, que por sus características estéticas podía asociarse también con la audición. Lo importante a pesar de que la imagen de la caligrafía japonesa era directamente la que estaba relacionada con la audición, así lo confirma el autor, era que el alumno explicara con sus propias palabras la sensación auditiva de atonalidad y no estructura con cualquiera de las dos imágenes. En definitiva, de lo que se trataba con este planteamiento reflexivo y asociativo era de comprobar el grado de madurez estética adquirido por el alumno.
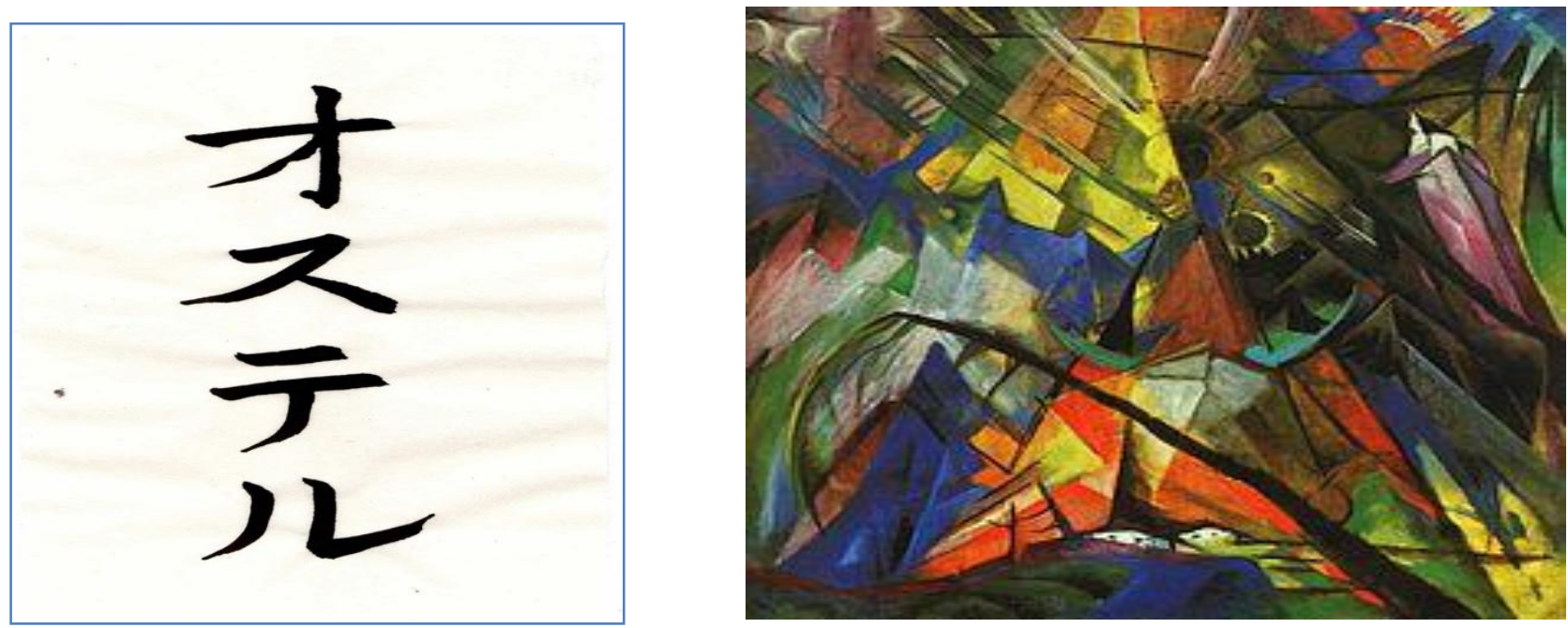

Figura 3. ¿ con qué imagen de las que se proponen a continuación, asociarías la siguiente audición? y ¿por qué?

PREGUNTAS $\mathrm{N}^{\circ}$ 8, 9 y 10. Para este conjunto de preguntas se ha seleccionado la obra de L. Berio Sequenza III, para voz. Esta pieza musical resulta interesante pues reúne en sí misma muchos elementos que con bastante frecuencia son utilizados en la estética musical contemporánea: el tratamiento no convencional de la voz, la atonalidad, o el tratamiento del sonido entendido por sus propias características sonoras, descontextualizado de su procedencia. En la cuestión $\mathrm{n}^{\mathbf{o}} 8$ se preguntaba sobre cómo se utilizaba la voz en la pieza que se estaba escuchando; en la pregunta $\mathrm{n}^{\circ} 9$ se aludía a la notación no convencional y en la $\mathrm{n}^{\mathbf{0}} 10$ se presentaban dos proyecciones de notación no convencional a la vez que sonaba la audición, debiendo elegir la partitura correcta. 
PREGUNTAS $\mathrm{N}^{\mathrm{o}}$ 11, 12 y 13. Para estas preguntas se ha utilizado la obra de O. Messiaen, Quatuor pour la fin du temps. I Liturgie de cristal. Esta obra representa un punto de inflexión en la historia de la música y en la vida compositiva del autor. Concretamente el primer movimiento, Liturgie de cristal del que sólo se propuso en audición el primer minuto y medio aproximadamente, destaca por el tratamiento del cello y el piano como instrumentos de acompañamiento rítmico. El violín y el clarinete tienen el protagonismo melódico, y son estos aspectos básicos sobre los cuales han versado las cuestiones. Concretamente en la pregunta $n^{\circ} 11$ se le pedía al alumno que discriminara el timbre de los instrumentos que realizaban la melodía y los que hacían el acompañamiento. En la pregunta $\mathrm{n}^{\mathbf{o}} 12$ se ha vuelto a recurrir a la grafía no convencional asociada en este caso a lo que estaba interpretando el piano, un conjunto de acordes muy marcados y a modo de ostinato rítmico y armónico (ver figura 4):

a.

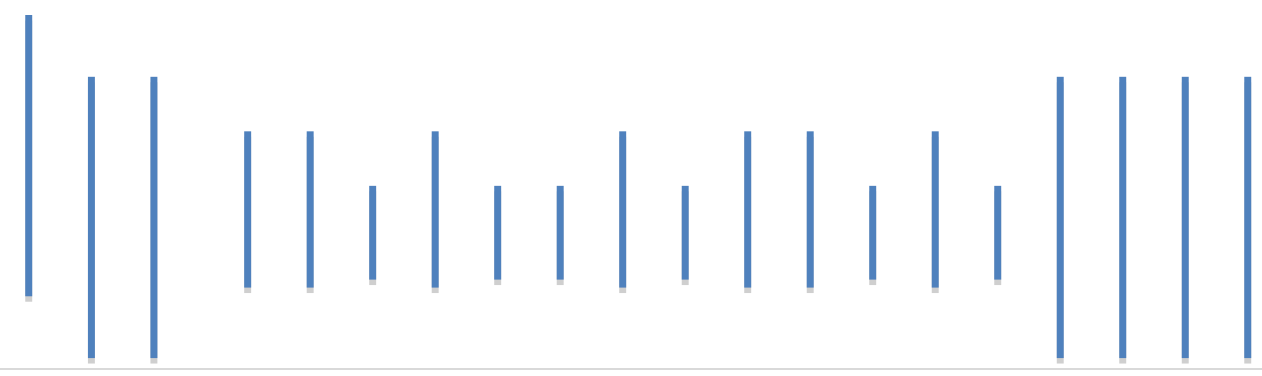

b.

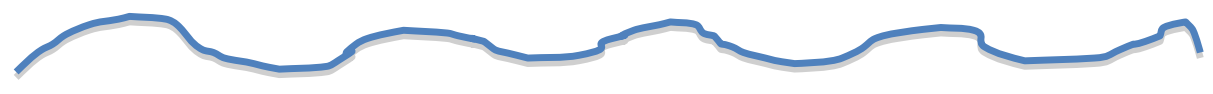

Figura 4. ¿Qué grafía representa mejor al piano que suena en esta audición?

Finalmente en la pregunta $n^{\circ} 13$ el alumno debía justificar la atonalidad de la obra escuchada con sus propias palabras. Esta pregunta abierta trataba de medir el grado de madurez y reflexión del alumno en cuanto a la utilización de conceptos coherentes y alusivos a la audición propuesta.

PREGUNTAS No 14,15 y 16.

Para este conjunto de preguntas se ha seleccionado la obra de G. Crumb Black Angels. Threnody I: Night of the electric insects. Esta pieza resulta atractiva por su sonoridad pues reúne muchas de las características a las que se suele recurrir en la música contemporánea, como la utilización de instrumentos de forma no convencional, la exploración del sonido o la música textural, todo ello partiendo de un cuarteto de cuerda tradicional.

La pregunta $\mathrm{n}^{\circ} 14$ pretendía que el alumno discriminara los timbres que estaban sonando y que no son habituales junto al cuarteto de cuerda, los cuales en este caso eran instrumentos de percusión no determinada tipo tam-tams, gongs, copas de cristal con agua y sonidos producidos por la voz.

En la pregunta $n^{\circ} 15$ se trataba de percibir los efectos texturales del conjunto instrumental de entre varias opciones de respuesta alusivas a la textura; la pregunta 16 era abierta y pretendía que el alumno justificara cómo comprendía mejor la audición a través de la visualización de la interpretación de ésta o únicamente escuchándola en audio. Se pretendía valorar el grado de madurez del alumno justificando su nivel de comprensión ante una obra de música contemporánea presentada en dos formatos diferentes.

PREGUNTAS No 17, 18 y 19. Para estas tres cuestiones se seleccionó la obra de K. Penderecki Threnody for the Victims of Hiroshima. Esta composición se eligió por sus características especiales tanto a nivel estético como compositivo. Destaca tímbricamente por estar compuesta para 52 instrumentos de cuerda, tratados en ocasiones no convencionalmente. Es una pieza que trata el sonido de forma textural, utiliza una notación no convencional y es muy descriptiva e impactante. Se ha presentado auditivamente el primer minuto aproximadamente. 
En la pregunta $\mathrm{n}^{\circ} 17$ se trataba el timbre de la obra, en la 18 se preguntaba acerca de la textura y en la 19, la cual era una pregunta abierta, se trataba de medir el grado de madurez del alumno a la hora de exponer o describir los elementos y recursos musicales que el compositor había utilizado en la audición, para crear el clima de tensión que se escuchaba manifiestamente en la obra.

PREGUNTA $N^{\circ} 20$. Es una pregunta abierta y no se presenta con ninguna audición, pues se ha pretendido que el alumno describa con sus palabras qué es la atonalidad. El hecho de preguntar sobre esta categoría es porque la atonalidad es una característica bastante recurrida en la estética contemporánea independientemente de pertenecer a una corriente estilística u otra. Todas las audiciones presentadas en el cuestionario han tenido como elemento común la atonalidad, por ello a modo de resumen comprensivo y reflexivo final se ha propuesto esta cuestión.

\section{TRIANGULACIÓN DE LOS RESULTADOS}

La experiencia ha tenido una aplicación metodológica cuasi-experimental, con dos grupos intactos pertenecientes a $3^{\circ}$ de la ESO, los datos que se han obtenido por tanto se han analizado desde un punto de vista cuantitativo y cualitativo. Los instrumentos de recogida de datos, como se ha comentado anteriormente, han sido diversos: un cuestionario informativo acerca del perfil de la muestra, un cuestionario test y post test y el cuaderno de campo del profesor, básicamente centrado en la observación.

En primer lugar, partiendo del cuestionario informativo, se ha contado con una muestra cuya edad oscilaba entre los 14 y 15 años, con una igualdad en cuanto a número de chicos y chicas en general, aunque desigualdad en la distribución de estos, entre los dos grupos. No se ha considerado este hecho como significativo. Los gustos musicales de la muestra oscilaban entre los habituales frecuentados por los adolescentes, no destacando la música clásica en ninguno de ellos.

Por otra parte, la muestra no contaba con una presencia significativa de alumnos con conocimientos musicales previos y adquiridos fuera del ámbito académico obligatorio. La calificación obtenida en la asignatura de música en el trimestre anterior fue moderadamente superior en el grupo experimental, con una media de 5,18 frente a un 4,66 del grupo control. El interés por la asignatura estaba bastante equiparado en ambos grupos, destacando en el grupo control un $9 \%$ de alumnos sin ningún interés por la asignatura.

Desde la aproximación cuantitativa, con los resultados pre-test, se constató que la muestra no seguía una distribución normal, ante lo cual se tuvieron que aplicar para el análisis de los datos pruebas no paramétricas. A pesar de que algunas son equivalentes a la paramétricas habituales, no ofrecen tantas posibilidades.

La prueba no paramétrica $U$ de Mann-Whitney que se pasó a la muestra con los datos del pretest, dio como resultado que existían diferencias significativas entre el grupo experimental y el control. Las diferencias eran moderadas, no obstante existían, pues $\mathrm{p}<00^{\prime} 05$, siendo $\mathrm{p}=0^{\prime} 041$. A nivel descriptivo y desde un punto de vista cualitativo se observó también que existían diferencias aunque moderadas entre los dos grupos, esto se comprobó con las variables independientes de la parte informativa del cuestionario relacionadas con la nota en la asignatura de música en el trimestre anterior y el interés por la asignatura. Al compararse ambos grupos en estas variables se demostraron descriptivamente diferencias moderadas de partida. Así, la nota media del grupo experimental en el trimestre anterior era de 5,18 y la del grupo control de 4,66.

En cuanto al interés por la asignatura lo único que cabe destacar era un mayor número de alumnos en el grupo control sin ningún interés.

Desde el punto de vista del profesor que ha realizado el estudio y atendiendo al cuestionario informativo inicial que recogía el perfil de la muestra, los grupos estaban bastante equiparados tanto en el momento de inicio de la experiencia como a lo largo del curso que había transcurrido, por ello se decidió proseguir con ella. Quizá el grupo control presentaba un mayor porcentaje de alumnos que no tenían una trayectoria positiva en la asignatura, no obstante partiendo de las medias en la asignatura en trimestres anteriores, la diferencia no era significativa desde un punto de vista descriptivo. 
Siguiendo con la metodología cuantitativa, se pasó de nuevo la prueba de $U$ de Mann-Whitney con los resultados del post-test. En esta ocasión los resultados no mostraron diferencias significativas entre ambos grupos, pues $p>0$ ' 05 , siendo $p=0$ ' 154 . Ante esto se podía deducir que no destacaba una metodología sobre la otra.

Desde la metodología cualitativa y de acuerdo con los datos estadísticos anteriores, tampoco se presentaron diferencias significativas en los resultados post-test no obstante sí moderadas. El grupo experimental obtuvo resultados tímidamente superiores al grupo control con una media de 7 , frente al 6,26 respectivamente tal y como se aprecia en la Figura 5.

\section{Puntuaciones}

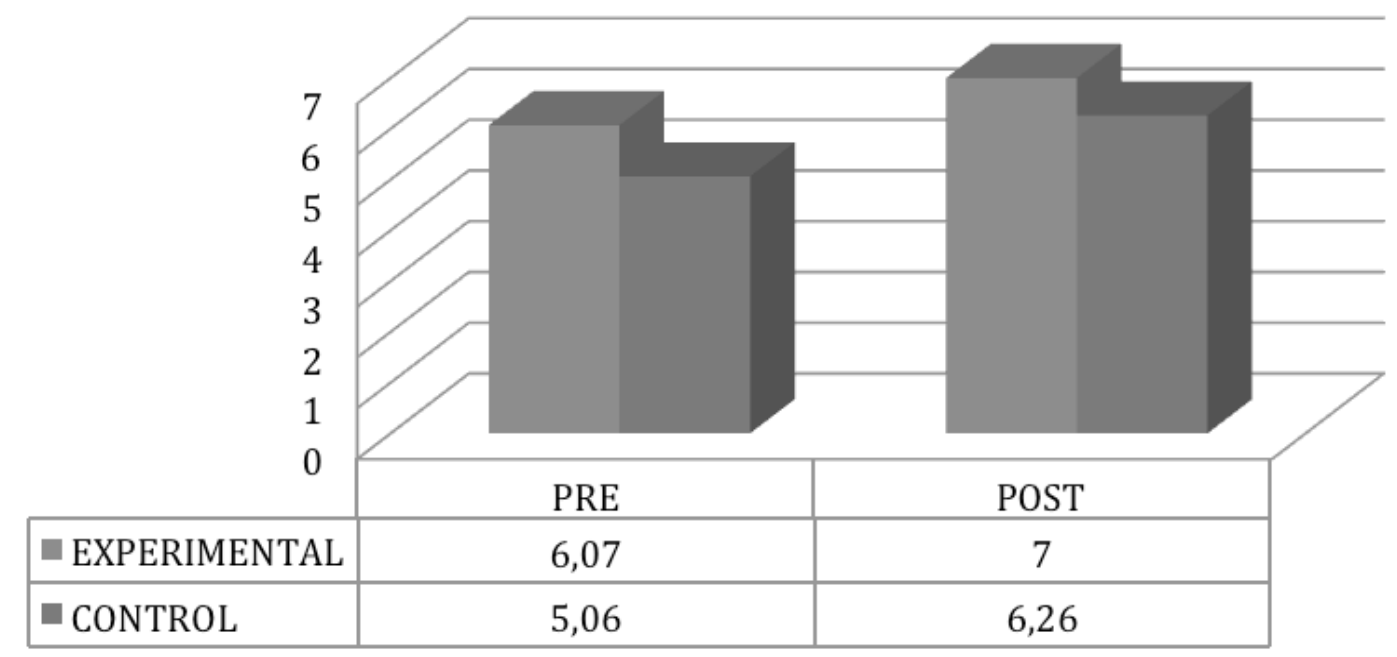

Figura 5. Comparación de resultados del pre-test y post-test entre el GE y GC.

La aproximación metodológica cualitativa ha permitido una interpretación más minuciosa de los datos a partir de la observación directa del profesor, el cuaderno de campo y sobre todo a través de la categorización de las preguntas del cuestionario quedando éste dividido en 5 categorías:

Categoría 1: Cualidades del sonido trabajadas desde la música contemporánea: timbre, altura, intensidad, duración. En este tipo de categoría se han englobado preguntas cuya característica común era la discriminación auditiva de alguna cualidad del sonido, desde una propuesta auditiva contemporánea. En general el grupo experimental, aunque de forma moderada obtuvo mejores resultados en el post-test en las preguntas de discriminación auditiva englobadas en esta categoría, ya que su tratamiento metodológico en el aula se basó en la audición activa desde diferentes enfoques. El grupo control por su parte tuvo resultados moderadamente inferiores en este tipo de preguntas, aunque en algunas cuestiones referidas a la discriminación de conceptos generales como el tempo quedó igualado al grupo experimental.

Categoría 2: Elementos de la música: melodía, acompañamiento, textura, estructura. En esta categoría los resultados del grupo experimental fueron moderadamente mejores, pues los alumnos en la mayor parte de las cuestiones debían describir con sus propias palabras o escoger respuestas relacionadas con los elementos de la música como la melodía o la textura. En el caso de las descripciones realizadas por los alumnos o en las discriminaciones tímbricas de la melodía, el grupo experimental se mostró superior, posiblemente, como se ha explicado en la categoría anterior, es debido a el tipo de planteamiento metodológico seguido por este grupo, en donde se ha potenciado la reflexión escrita partiendo de la audición. No obstante en aspectos como la textura o la discriminación melódica partiendo de una propuesta tipo morfológica los resultados han estado igualados en ambos grupos.

Categoría 3: Características de la música contemporánea: atonalidad, notación no convencional, 
sonidos no convencionales. En el cuestionario había una tipología de preguntas que se referían a características de la música contemporánea. En este tipo de categoría, en la mayor parte de las cuestiones que en ella se integran, obtuvo mejores resultados aunque de forma moderada, el grupo experimental. Estos datos se refieren a aquellas cuestiones en las que se requería el uso de terminología apropiada para describir la audición o se debía discriminar auditivamente algún aspecto en concreto referido a las características de la música contemporánea o al seguimiento de una partitura de notación no convencional. En otro tipo de preguntas de índole más teórica, en donde se pedía al oyente que diera una definición objetiva sin partir de ningún ejemplo auditivo, el grupo control a pesar de estar igualado con el experimental, fue más técnico en el uso terminológico posiblemente debido al tratamiento metodológico utilizado en su Unidad Didáctica.

Categoría 4. Audición/Reflexión: relación sonido-representación gráfico-morfológica; audición/reflexión. En esta categoría destaca un equilibrio entre ambos grupos. El grupo control no ha sido superior en cuanto a resultados en ninguna de las preguntas que engloban pues obtuvo resultados bastante igualados a los del grupo experimental. Sólo en las preguntas que requerían una explicación reflexionada pero partiendo de la discriminación auditiva por parte del oyente sobre algún aspecto relacionado con una audición, destacó en resultados moderadamente superiores en el post-test. El grupo experimental en cambio, en preguntas de reflexión estética, en general, se denotó un avance y madurez por ambas partes.

Categoría 5. Gusto por la música contemporánea. En esta categoría ambos grupos han obtenido resultados similares: Lo único que cabe comentar es la diferente tesitura de las respuestas en ambos grupos. En el de control un mayor número de alumnos recurrieron a una terminología y reflexiones trabajadas en la Unidad Didáctica magistral. En cambio el grupo experimental, a la hora de justificar su gusto o no hacia la música contemporánea, ha recurrido a respuestas más heterogéneas e intuitivas.

Atendiendo a lo anterior, el grupo experimental ha obtenido mejores resultados, aunque de forma moderada, en la mayor parte de las preguntas y, especialmente, en las abiertas que requerían una explicación u opinión partiendo de una audición propuesta, junto con las preguntas de carácter discriminatorio auditivo. Se puede deducir así que la metodología experimental basada en un entrenamiento auditivo vivencial y activo a la que estuvo expuesto el grupo, posiblemente haya resultado un tanto superior.

Cabe añadir el hecho de que en el grupo experimental mejoran más alumnos, concretamente un $85 \%$ frente a un $68 \%$ que lo hacen en el grupo control (ver figuras 6 y 7). A pesar de ello, ambos grupos han mejorado significativamente en el post-test, pues además de denotarse a nivel descriptivo (en el pre-test el grupo experimental obtuvo una media de 6,07 y en el post-test de 7, frente a una media del grupo control en el pre-test de 5,06 y de 6,26 en el post-test). Se ha demostrado estadísticamente, ya que se pasó a ambos grupos la prueba de Willcoxon para muestras apareadas dando resultados significativos en ambos grupos. Para el grupo experimental se obtuvo $\mathrm{p}<0^{\prime} 05$, siendo $\mathrm{p}=0^{\prime} 000$ y para el grupo control $\mathrm{p}<00^{\prime} 05$ siendo $\mathrm{p}=0^{\prime} 005$.

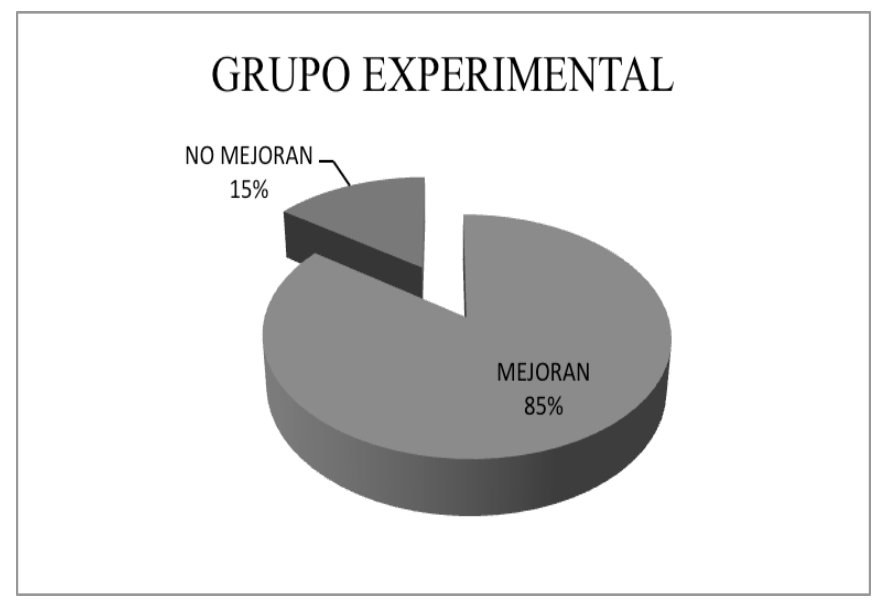


Figura 6. Porcentaje de alumnos que mejoran en el GE.

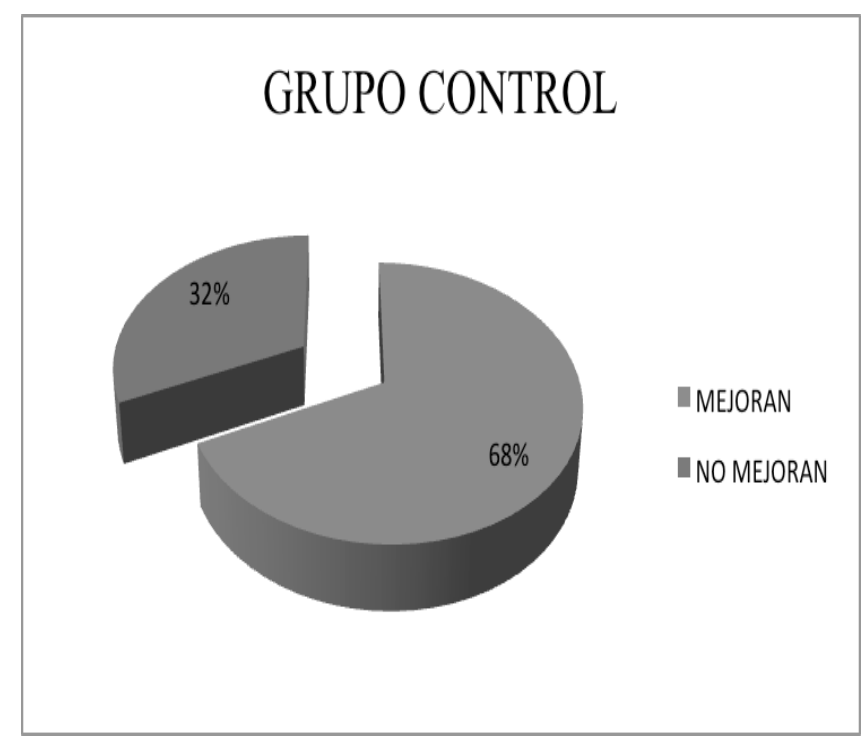

Figura 7. Porcentaje de alumnos mejoran en el GC.

Desde el punto de vista del profesor, los alumnos del grupo experimental han ido adquiriendo una mayor solidez en cuanto a discriminación auditiva y comentario reflexionado de lo que estaban escuchando. Esto se ha podido constatar en los cuadernos de ejercicios y audiciones individuales, hecho que luego se ha reflejado en los resultados post-test. El grupo control por su parte desde un punto de vista auditivo, a pesar de haber escuchado las mismas obras, el tratamiento y forma de enfrentarse a ellas ha sido el del comentario de audición tradicional, sin detenerse en aspectos reflexivos más allá de lo coherente, no obstante también su actitud ha sido positiva y ha ido madurando y mejorando a lo largo de la experiencia.

En la primera pregunta de la encuesta de valoración, la cual era contestada en el pre-test y en el post-test, se han obtenido resultados similares en ambos grupos. Las dos metodologías han conseguido después de su aplicación, que la actitud hacia la música contemporánea por parte de los alumnos sea más madura y reflexionada. El conocimiento adquirido de forma vivencial o más tradicional ha mejorado la actitud y la comprensión hacia ella. Se ha llegado a las mismas conclusiones en el cuaderno de campo; del desconcierto inicial en el pre-test ante la música contemporánea propuesta, la actitud y forma de enfrentarse a ella fue gradualmente mejorando y variando. De hecho, los comentarios pasaron de ser de opinión y poco fundamentados acerca del agrado o no de la música escuchada, a comentarios más reflexivos, interesados y comprensivos.

En este instrumento de recogida de datos, se ha constatado el hecho de que la metodología experimental ha gustado a la mayor parte del grupo al que ha sido aplicada. Quizás los primeros días resultaron desconcertantes, pero poco a poco fueron adaptándose a la nueva forma de trabajar, hasta el punto de que el grupo en general se fue relajando y la motivación movió a la mayor parte del alumnado. Si atendemos a los resultados de la segunda pregunta de la encuesta de valoración, se complementan con lo que se acaba de exponer, pues un 95\% de los alumnos de este grupo opinan con agrado acerca de la metodología empleada en su clase. Éstos contrastan moderadamente con el grupo control que cuenta con un menor porcentaje de alumnos que ha opinado favorablemente. A pesar de este menor porcentaje, cabe comentar que el grupo control se mostró muy atento e interesado por los contenidos trabajados y que la novedad y curiosidad hacia ellos provocó que el desarrollo metodológico tradicional pasara más desapercibido en principio, aunque posteriormente opinaran desfavorablemente hacia él.

La información anterior se complementa con la tercera pregunta de la encuesta de valoración. Aquí los alumnos respondían acerca del grado de comprensión de los contenidos tratados en la Unidad Didáctica. El grupo experimental ha presentado un porcentaje mayor de alumnos que dicen 
haber entendido completa o parcialmente los contenidos, concretamente un $75 \%$, frente a un $53 \%$ del grupo control. Posiblemente se puede justificar este menor porcentaje según las anotaciones del profesor, por la gran cantidad de contenido teórico-conceptual tratado en la metodología del grupo control.

Así, los resultados estadísticos concuerdan bastante coherentemente con la metodología cualitativa. No existen diferencias significativas entre ambas metodologías, no obstante gracias a esta última aproximación metodológica se ha podido ser más minucioso en la interpretación de las diferentes cuestiones y se ha podido observar que la metodología experimental ha resultado, por una parte, más fructífera en cuanto al proceso de enseñanza-aprendizaje obteniéndose moderados, pero mejores resultados coherentes con los objetivos planteados en el trabajo. Por otra parte y atendiendo a las opiniones de los alumnos en la encuesta de valoración, esta metodología ha sido agradable de trabajar en clase por la novedad que para ellos suponía tratar un tema únicamente desde una perspectiva experiencial auditiva, por esto mismo han opinado que les ha favorecido en su aprendizaje. El grupo control por su parte también ha obtenido grandes avances, no obstante esta mejoría se ha basado en comprender a nivel teórico y conceptual ciertos aspectos determinantes de la música contemporánea y no tanto a nivel práctico auditivo.

Atendiendo a las opiniones de la encuesta de valoración, se ha denotado una maduración en cuanto a nivel de respuestas, no obstante son más alumnos los que en el grupo control opinan no haber captado completamente todos los aspectos tratados en el tema, posiblemente por una excesiva presencia del elemento conceptual.

\section{CONCLUSIONES}

Partiendo de la pregunta inicial de investigación en la que se cuestionaba qué metodología docente resultaría más idónea para la comprensión de la música contemporánea por parte del alumnado de $3^{\circ}$ de la ESO y después de la experiencia, se podría decir que los resultados obtenidos no demuestran significativamente la primacía de una metodología sobre la otra. No obstante, se ha podido observar gracias al planteamiento metodológico cuasi-experimental mixto (cuantitativo y cualitativo) ciertos aspectos que situarían a la metodología experimental por encima de la magistral.

Los cuasi-experimentos son habituales e idóneos para el ámbito educativo y así se ha constatado en este trabajo, en el cual se contaba con una muestra formada por dos grupos intactos. Sin poder realizar un experimento puro, el cuasi experimento ha permitido estudiar y comprender desde un punto de vista cuantitativo los resultados, los cuales se han obtenido a través de un cuestionario pretest y post-test. Sin embargo, dado el reducido tamaño de esta muestra, N=41, se han presentado bastantes problemas. Por una parte, la muestra era la formada por los grupos que durante el año académico 2012/2013 le correspondían laboralmente al docente, también investigador de este trabajo, de ahí su tamaño reducido. Por otra, la problemática residió en que en el punto de partida de la investigación en su vertiente cuantitativa se detectó una distribución no normal de la muestra. Este aspecto pudo explicarse no a través de pruebas estadísticas sino más bien gracias a la interpretación cualitativa y a la observación del profesor, que consideró poco significativas las diferencias entre ambos grupos.

Cabe decir que aún habiendo realizado un cuasi-experimento en este trabajo, la aproximación cualitativa resultó mucho más fructífera pues apoyada por la interpretación y observación docente permitió comprender y denotar que el grupo experimental había alcanzado los objetivos propuestos en mayor medida que el grupo control.

Por las características de esta investigación, no se ha pretendido generar ninguna teoría, no obstante, pretende ser una propuesta para el docente que quiera aproximarse a la didáctica de la música contemporánea en aspectos como el acercamiento vivencial a esta música, escuchándola desde diferentes tipologías de audición o el trabajo cooperativo a la hora de abordar el componente contextual e histórico necesario para comprender toda audición. Todo con el objetivo final de entrenar el oído del alumno hacia este tipo de estética musical y de una forma muy práctica.

El hecho de que el propio docente fuese el investigador, aspecto que podía de alguna forma 
sesgar determinados aspectos metodológicos, tuvo por otra parte un componente beneficioso ya que la observación directa permitió una mejor comprensión.

Se han obtenido ciertos datos, como se expone en la figura 8, que demuestran que la metodología experimental ha sido más apropiada para la consecución de algunos aspectos relacionados con la comprensión de la música contemporánea y planteados a través de las respectivas Unidades Didácticas. Concretamente en el grupo experimental se puede denotar un mayor porcentaje de alumnos que han entendido mejor los contenidos expuestos en su unidad didáctica que el grupo control.

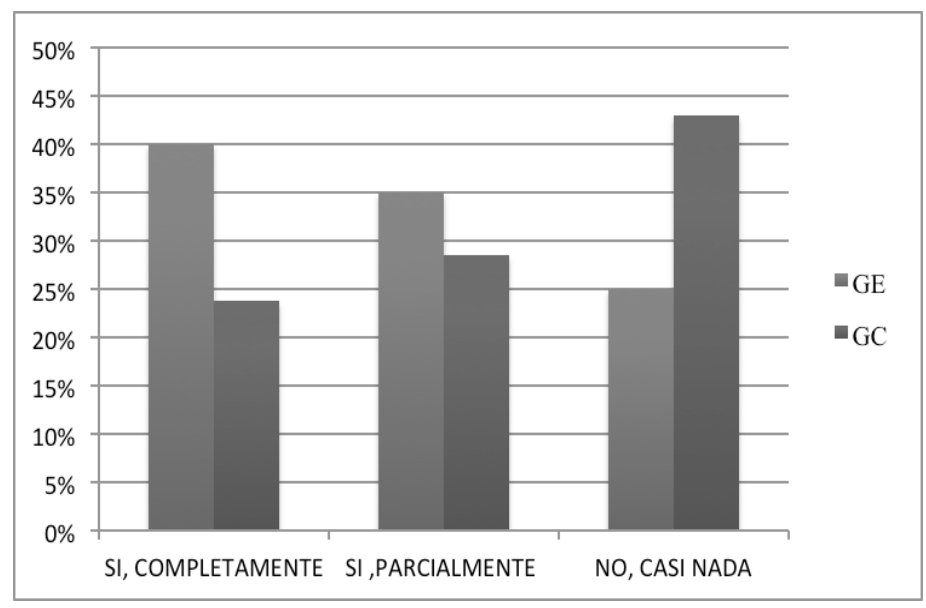

Figura 8. Comparación de los porcentajes acerca de la comprensión de los contenidos trabajados.

Se considera importante destacar el hecho de que los resultados del grupo control, sobre todo los procedentes de las preguntas abiertas del cuestionario y de la encuesta de valoración, han sido producto de algo que habitualmente ocurre en este tipo de metodologías más tradicionales. Los alumnos acaban contestando conceptos y elementos, fruto de un proceso de memorización o de excesiva reiteración teórica en el aula.

El grupo experimental, sin ser excesivamente superior en cuanto a resultados, ha mostrado una tipología de respuestas abiertas más intuitivas y reflexionadas, partiendo directamente del ejemplo auditivo propuesto, ante esto se puede afirmar que su aprendizaje ha sido significativo. Quizás no han recurrido a una terminología y conceptos excesivamente cultos y propios de la estética contemporánea, como sí lo ha hecho el grupo control, posiblemente procedente de un proceso de memorización o reiteración conceptual, pero no obstante se ha denotado construcción de conocimiento, asimilación de la información y reflexión.

El grupo control por tanto no ha desarrollado tan acusadamente un aspecto que es de los más importantes en la educación musical, la audición y el saber escuchar, ya que la metodología tradicional no potencia excesivamente esto. La diferencia posiblemente oscile en que a largo plazo el grupo experimental podrá utilizar este entrenamiento auditivo y las capacidades adquiridas, en otros contextos musicales, mientras que en el grupo control la experiencia con la música contemporánea quedará limitada en algunos aspectos por su capacidad memorística.

Respecto a los objetivos de la investigación, se ha intentado ser consecuente y posiblemente se hayan conseguido los dos planteados en este estudio, consistentes los dos primeros en la comparación de dos metodologías aplicadas para la comprensión de la música contemporánea y en la comprobación de si existen mejores resultados de una sobre la otra. Con respecto al objetivo c), el cual realmente no se ha considerado como objetivo de la investigación, pero sí como objetivo intrínseco y subyacente durante todo el proceso: trabajar la música contemporánea en el aula, se podría decir que en ambas metodologías se ha conseguido alcanzar, a través de la aplicación de sus respectivas Unidades Didácticas.

Resulta interesante, respecto a este aspecto, que el currículo propone muchas particularidades de la música contemporánea entre sus objetivos, pero una cosa es la propuesta teórica y otra la realidad 
en las aulas, en donde ésta no suele estar muy presente Urrutia (2012). Las razones son muchas, aunque entre ellas destacan la falta de preparación docente con respecto a esta música y el no gusto hacía ella derivado posiblemente de la no comprensión Mateos (2007). Ante esto, este objetivo c) es consecuencia de un compromiso personal de quien ha realizado esta investigación (docente de los grupos que conforman la muestra y a la vez investigador en este experimento) por mejorar la práctica docente con respecto a la música contemporánea y ser consecuente con una realidad que parece que en el campo de la música en ocasiones no exista.

Se puede deducir, por tanto, que la comprensión de los contenidos de las Unidades Didácticas ha favorecido a que el gusto o forma de enfrentarse a la música contemporánea cambie favorablemente. Con estos resultados posiblemente se ha logrado además de los objetivos planteados, otro muy importante en todo currículo artístico musical y que está como específico en este trabajo: el enfrentarse a cualquier estética desde el respeto y el pensamiento crítico, más aún, si estamos tratando con la música contemporánea, que tanto esfuerzo le ha costado para ser parte normalizada de las programaciones de aula. Como opina Hemsy de Gainza (1995:22): "La escuela no puede ignorar los lenguajes actuales de comunicación sonora".

Los objetivos específicos propuestos en este trabajo, además de en cada una de las Unidades Didácticas, pretendían en líneas generales, que al realizar una audición de música contemporánea o al asistir a un concierto, los alumnos supieran intuir esta música, reconocerla estéticamente en términos generales, y que entendieran, comprendieran e incluso lograran extraer de ella elementos habitualmente recurrentes en los diferentes estilos compositivos. Ante esto, posiblemente la metodología experimental haya estado más cerca de conseguir los objetivos específicos en todos sus aspectos dadas sus características y el grupo control sólo parcialmente, ya que en lo referente a la reflexión auditiva y discriminatoria, los resultados han quedado por debajo del grupo experimental.

A nivel docente ha resultado muy enriquecedor trabajar con ambos grupos y observar en cada momento del proceso de enseñanza-aprendizaje cómo se enfrentaban a la música contemporánea. Se produjeron en poco tiempo muchos acontecimientos estéticos y auditivos que fueron desde el desconcierto inicial, a la motivación y comprensión final en muchos casos. Ha quedado demostrado por parte de la muestra en general, una capacidad de adaptación impulsada por la motivación de trabajar contenidos novedosos derivados de esta música. A lo largo de este proceso didáctico, independientemente de la metodología utilizada, se han podido mejorar y adoptar nuevos mecanismos didácticos y metodológicos para transmitir esta música o para trabajar a partir de ella, tanto desde la metodología magistral como en la experiencial.

La sociedad, y los alumnos como parte de ésta, conocen el arte y la tecnología de su tiempo, deben por ello enfrentarse con juicio crítico y fundamentado a la música culta contemporánea sin pretender con esto cambiar sus preferencias musicales; atendiendo a este aspecto, ambas metodologías, posiblemente por el carácter auditivamente especial de los contenidos trabajados, han provocado después de su aplicación, un acercamiento más positivo y maduro hacia la música contemporánea.

Ha resultado interesante confirmar el hecho de que el tipo de metodología aplicada al grupo experimental ha sido positivamente valorada por parte de los alumnos. Éstos en general se han sentido motivados, han sido conscientes de su proceso de aprendizaje y además se han divertido. El realizar las clases desde un punto de vista esencialmente práctico y vivencial ha provocado, motivación, implicación y curiosidad. Cualquier tipo de música trabajada desde un punto de vista vivencial y práctico puede resultar positiva y fructífera, pero además la música contemporánea contiene por sus peculiaridades estéticas todos los ingredientes para ser trabajada de esta forma. El único inconveniente es que el trabajar así requiere tiempo y planificación pues el proceso de enseñanza aprendizaje es más completo y profundo. La metodología tradicional no ha sido mal valorada por parte del grupo control, posiblemente porque la novedad y originalidad de los contenidos trabajados ha amenizado el aprendizaje y ha provocado también en este grupo la comprensión, aunque en otro nivel más limitado y menos significativo.

La metodología experimental cumple por tanto con las exigencias del currículum tanto a nivel de contenidos conceptuales, procedimentales y actitudinales. El constructivismo sobre el que se ha 
fundamentado y la capacidad de reflexión que ha provocado en el alumno se pueden trasladar a cualquier otro contexto musical y extra-musical.

En definitiva, el hecho de comparar dos metodologías aplicadas para la comprensión de la música contemporánea en la ESO ha dado sus resultados y en muchos planos diferentes. Posiblemente y a través de los datos obtenidos en la experiencia, se ha puesto en evidencia el hecho de que la música contemporánea puede ser tratada en cualquier nivel educativo, inclusive en el que se ha elegido, pues ha quedado demostrado que la comprensión ha provocado el respeto y el juicio crítico a la hora de enfrentarse a esta música. La audición activa, es solo el punto de partida de una formación que puede seguir completándose más profundamente con la interpretación, la experimentación sonora y la creación en la ESO.

Por otra parte, han quedado demostradas las posibilidades que tiene la música contemporánea y lo motivadores que pueden resultar este tipo de contenidos secuenciados minuciosa y constructivamente. Si esto se puede aplicar en la ESO e incluso como se ha explicado en el estado de la cuestión, en la educación Primaria, cabe preguntarse si tendría cabida en las enseñanzas profesionales de música el trabajar en algún momento y de forma activa la música contemporánea en todas las asignaturas que así lo permitieran, lenguaje musical, coro o historia de la música. Posiblemente beneficiarían a la interpretación, enfrentándose a ella ahora desde una mejor comprensión auditiva y estética, y no desde la barrera que en muchos casos se interpone entre el intérprete profesional y la música contemporánea.

Se podría pensar que comparar dos metodologías tan diferentes como la magistral y la experiencial, posiblemente daría unos resultados previstos y que la metodología experiencial simplemente por sus propias características vivenciales resultaría más motivadora y consecuentemente ofrecería mejores resultados. En parte esta afirmación es cierta. El grupo experimental obtuvo mejores resultados en aspectos referidos a la reflexión y discriminación auditiva que consecuentemente están relacionados con la comprensión. Ninguna metodología por tanto ha resultado en todos sus componentes idónea. Lo más interesante quizá reside en tratar de combinarlas y aplicarlas estratégicamente para ofrecer así resultados más enriquecedores en todos los aspectos.

\section{Referencias}

Adessi, A. R. (2005). Analysis and perception in post-tonal music: an exemple from Kurtàg's string Quartet op.1. Psychology of music, 33, 94-116. Doi: 10.1177/0305735605048015.

Bimberg, S. (1987). Investigations on the change of attitudes towards contemporary music. Bulletin of the council for research in music education, 91, 6-9.

Boal, G., Ilari, B. \& Monteiro, F. (2006). Children's response to 20th century art music, in Portugal and Brazil. Proceedings of the 9th International Conference on Music Perception and Cognition. Bologna. Italy, 588-595.

Chion, M. (1990). La audiovisión. Barcelona: Paidós.

Cook T. D. \& Campbell D. T. (1986). The casual assumptions of quasi-experimental practice. Synthese, 68, 145-180. Doi:10.1007/BF00413970.

Copland, A. (1939). Cómo escuchar la música. Madrid: Fondo de Cultura.

Cureses de la Vega, M. (1998). La música contemporánea en el aula de secundaria. Aula Abierta, 71, 211-232.

Decreto 112/2007 del 20 julio del Consell, por el que se establece el currículo de la Educación Secundaria Obligatoria en la Comunidad Valenciana. 2007/9717. DOCV núm. 5562.

Delalande, F. (1995). La música es un juego de niños. Buenos Aires: Ricordi.

Espinosa, S. (2007). La música electroacústica en la escuela. Apuntes para la aplicación de una metodología de audición. Eufonía, 40, 18-31.

Francès, R. (1958). La perception de la musique. París: Vrin.

Haak, P. (1992). The acquisition of music listening skills. En Colwell, R. (Ed.) Handbook of research on music teaching and learning: a project of the Music Educators National Conference 
(pp. 451-465). Nueva York: Schirmer Books.

Hemsy de Gainza, V. (1995). Didáctica de la música contemporánea en el aula. Música y Educación, 24, 17-24.

Imberty, M. (1993). How do we percieve atonal music? Suggestions for a theoretical approach. Contemporary Music Review, 9, 1, 325-337. Doi:10.1080/07494469300640541.

Laucirica, A., Almoguera, A., Eguilaz, M. J. \& Ordoñana, J. A. (2012). El gusto por la música contemporánea en estudiantes de grado superior de conservatorios de música. Leeme, 30, 1-20.

Ley Orgánica 2/2006, de 3 de Mayo, de Educación.

Marco, T. (2007). La creación musical en el s. XXI. Navarra: Universidad pública de Navarra.

Mateos, D. (2007). La música contemporánea y los futuros maestros de educación musical. Tesis doctoral inédita. Universidad de Málaga.

Marín, M. J. (2003). La audición, primera fase para la apreciación musical. Leeme, 11, 1-3.

Muñoz, L. (2001). La enseñanza de la música contemporánea en la educación primaria y secundaria. Música d'Ara, 4, 25-34.

Ordoñana, J. A., Almoguera, A., Sesma, F. y Laucirica, A. (2006). La atonalidad en la enseñanza musical. Música y Educación, 66, 51-74.

Ordoñana, J. A. (2011). La estructura de la música atonal y las leyes de la percepción. Un estudio con profesorado y estudiantes de música. Tesis doctoral inédita. Universidad Pública de Navarra.

Palacios, F. (1994). La audición musical, punto clave de la formación artística. Aula de innovación educativa, 24, 1-5.

Palacios, F. (2001). Orden, memoria y creatividad en la audición musical. En Atance, J. y Oriol, N. (Dir.). La educación artística, clave para el desarrollo de la creatividad (pp. 95-104). Madrid: Ministerio de Educación, Cultura y Deporte.

Pascual, P. (2011). Escuchar música del s. XX: Un estudio del repertorio, los criterios para seleccionarlo y una aportación didáctica. Madrid: UNED.

Paynter, J. (1999). Sonido y estructura. Madrid: Akal.

Schafer, R. M. (1969). El nuevo paisaje sonoro. Buenos Aires: Ricordi.

Schaeffer, P. (1988). Tratado de los Objetos Musicales. Madrid: Alianza Editorial.

Serafine, M. L. (1988). Music as a cognition. New York: Columbia University Press.

Sloboda, J. (1985). La mente musical: La psicología cognitiva de la música. Madrid: Machado.

Swanwick, K. (1988). Música, pensamiento y educación. Madrid: Ministerio de Educación y Ciencia.

Trallero, C. (2008). El oído musical. Documents de Treball, 18. Barcelona: Universitat de Barcelona.

Urrutia, A. (2012). La presencia y el uso de la música contemporánea en la Educación Secundaria: Un estudio en la Comunidad Autónoma del País Vasco. Tesis doctoral inédita. Universidad de Navarra.

Valls, A. (2010). La música contemporánea en el aula de primaria. Seminario Internacional de Investigación en Educación Musical. Universidad Complutense de Madrid.

Valls, A. \& Calmell, C. (2010). La música contemporània catalana a l'escola. Barcelona: Dinsic.

Vidal, J. F. \& Viladot, L. (2013). Paisajes sonoros en la formación inicial del profesorado. Investigación de calidad para mejorar la educación. Libro de comunicaciones. CIME13, 31-37. Tarragona.

Zamacois, J. (1975). Temas de estética y de historia de la música. Barcelona: Labor.

\footnotetext{
${ }^{1}$ El término Música Contemporánea está cargado de ambigüedad, pues el término contemporáneo, dependiendo del contexto en el que estemos ubicados, puede tener acepciones tanto conceptuales, como cronológicas o incluso
} 
geográficas. En este trabajo se va a utilizar el concepto Música Contemporánea entendido como la música clásica contemporánea y concretamente, dada la amplitud del término, se estará refiriendo a la expresión artística en el ámbito musical compuesta desde comienzos del s. XX según unos cánones de gran diversidad estética pero con un denominador común, que consistirá en la ruptura con la jerarquía tonal (Laucirica et al., 2012).

${ }^{2}$ Marco (2007) afirma que el concepto de música contemporánea es muy difícil de sistematizar, pero en cambio, resulta mucho más fácil de intuir y reconocer, por sus peculiaridades estilísticas. Así la comprensión de la música contemporánea en este trabajo y para este nivel educativo se entenderá como la capacidad que tenga el alumno de saber reconocer auditivamente la música contemporánea por sus peculiaridades estilísticas, sin ser necesario que la encasille en una vanguardia estilística $u$ otra.

${ }^{3}$ Los objetivos específicos de las Unidades Didácticas referidas, las cuales se aplicaron a un grupo de $3^{\circ}$ de la ESO de un Instituto de Educación Secundaria en la Comunidad Valenciana, parten del Decreto 112/2007 de 20 de julio, del Consell, por el que se establece el currículo de la Educación Secundaria Obligatoria en la Comunidad Valenciana.

${ }^{4}$ Hay que tener en cuenta las limitaciones que presenta en general la metodología cuasi-experimental, la correcta planificación, rigurosidad y ejecución del cuasi-experimento, supone en ocasiones casi la única alternativa de trabajo para que se pueda proporcionar la información adecuada sobre el impacto de un determinado tratamiento.

${ }^{5}$ El cuaderno está realizado desde una perspectiva constructivista, pues los propios alumnos lo fueron elaborando poco a poco y de forma individual. Se pretendía que a través de la secuenciación de las diferentes actividades auditivas, éstos fueran cada vez más autónomos en cuanto al comentario de las piezas escuchadas.

${ }^{6}$ Obviamente esta pregunta era interesante y determinante para la investigación, por eso ha sido respondida en ambos momentos de la investigación, por denotar posibles cambios de actitud después de la intervención didáctica, especialmente en el grupo experimental.

Manuscrito recibido el 21/02/2015 y evaluado anónimamente. Aceptado para su publicación el 23/05/2016. 